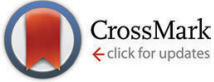

Cite this: Phys. Chem. Chem. Phys., 2016, 18, 31586

Received 20th October 2016, Accepted 8th November 2016

DOI: $10.1039 / c 6 c p 07197 j$

www.rsc.org/pccp

\section{Chemical vapor deposition-prepared sub-nanometer Zr clusters on Pd surfaces: promotion of methane dry reforming $\dagger$}

\author{
Lukas Mayr, ${ }^{\text {ab }}$ Xue-Rong Shi, ${ }^{a}$ Norbert Köpfle, ${ }^{a}$ Cory A. Milligan, ${ }^{\text {bc }}$ \\ Dmitry Y. Zemlyanov, ${ }^{b}$ Axel Knop-Gericke, ${ }^{d}$ Michael Hävecker, ${ }^{d}$ \\ Bernhard Klötzer ${ }^{a}$ and Simon Penner ${ }^{{ }^{a}}$
}

\begin{abstract}
An inverse $\mathrm{Pd}-\mathrm{Zr}$ model catalyst was prepared by chemical vapor deposition (CVD) using zirconium$t$-butoxide (ZTB) as an organometallic precursor. Pd-Zr interaction was then investigated with focus on the correlation of reforming performance with the oxidation state of $\mathrm{Zr}$. As test reactions, dry reforming of methane (DRM) and methanol steam reforming (MSR) were chosen. Depending on treatments, either $\mathrm{ZrO}_{x} \mathrm{H}_{y}$ or $\mathrm{ZrO}_{2}$ overlayers or $\mathrm{Zr}$ as sub-nanometer clusters could be obtained. Following the adsorption of ZTB on $\mathrm{Pd}(111)$, a partially hydroxylated $\mathrm{Zr}^{4+}$-containing layer was formed, which can be reduced to metallic $\mathrm{Zr}$ by thermal annealing in ultrahigh vacuum, leading to redox-active $\mathrm{Zr}^{0}$ sub-nanometer clusters. Complementary density functional theoretical (DFT) calculations showed that a single layer of $\mathrm{ZrO}_{2}$ on $\mathrm{Pd}(111)$ can be more easily reduced toward the metallic state than a double- and triple layer. Also, the initial and resulting layer compositions greatly depend on gas environment. The lower the water background partial pressure, the faster and more complete the reduction of $\mathrm{Zr}^{4+}$ species to $\mathrm{Zr}^{0}$ on $\mathrm{Pd}$ takes place. Under methanol steam reforming conditions, water activation by hydroxylation of $\mathrm{Zr}$ occurs. In excess of methanol, strong coking is induced by the $\mathrm{Pd} / \mathrm{ZrO}_{x} \mathrm{H}_{y}$ interface. In contrast, dry reforming of methane is effectively promoted if these initially metallic $\mathrm{Zr}$ species are present in the pre-catalyst, leading to a $\mathrm{Pd} / \mathrm{ZrO}_{x} \mathrm{H}_{y}$ phase boundary by oxidative activation under reaction conditions. These reaction-induced active sites for DRM are stable with respect to carbon blocking or coking. In essence, $\mathrm{Zr}$ doping of $\mathrm{Pd}$ opens specific $\mathrm{CO}_{2}$ activation channels, which are absent on pure metallic Pd.
\end{abstract}

\section{Introduction}

$\mathrm{ZrO}_{2}$ is commonly regarded as a highly stable, "irreducible" refractory oxide. Nevertheless, it is currently under investigation to expand its applicability as a catalyst for selective aldehyde oxidation. ${ }^{1}$ Regarding CO hydrogenation, the roles of different zirconia polymorphs in the synthesis of higher alcohols were studied both over pure and Pd- or Li-modified $\mathrm{ZrO}_{2}{ }^{2}$ It has also

\footnotetext{
${ }^{a}$ Institute of Physical Chemistry, University of Innsbruck, Innrain 80-82, Innsbruck, Austria. E-mail: simon.penner@uibk.ac.at; Tel: +4351250758003

${ }^{b}$ Birck Nanotechnology Center, Purdue University, 1205 West State Street, West Lafayette, IN 47907, USA

${ }^{c}$ School of Chemical Engineering, Purdue University, West Lafayette, Indiana, 47907, USA

${ }^{d}$ Department of Inorganic Chemistry, Fritz-Haber-Institute of the Max-Planck-Society, Faradayweg 4-6, D-14195 Berlin, Germany

$\dagger$ Electronic supplementary information (ESI) available: Overview of XPS Overlayer model, $\mathrm{Zr} 3 \mathrm{~d}$ core level region showing in situ CVD growth monitored at $673 \mathrm{~K}$, C 1s and $\mathrm{Zr} 3 \mathrm{~d}$ core level regions of molecularly adsorbed ZTB, summary of ZTB HREELS peak assignments, HREELS spectra of ZTB decomposition, X-ray diffractograms, MSR reaction profiles. See DOI: 10.1039/c6cp07197j
}

been shown to promote catalysts for methanol reforming processes. ${ }^{3}$ In this context, it has been successfully applied as a stabilizing support to prevent $\mathrm{CuO}_{x}$ nanoparticles from sintering, and therefore enhances the stability of methanol steam reforming catalysts. ${ }^{4} \mathrm{Zr}^{4+}$ ions have also been reported to play an important role as dopants in an $\mathrm{Au} / \mathrm{CeO}_{2}$ catalyst for $\mathrm{CO}$ oxidation ${ }^{5}$ and in sol-gel-synthesized photocatalysts. ${ }^{6}$ Interest in the chemical properties of $\mathrm{ZrO}_{2}$ polymorphs also arises from its application as YSZ (yttrium-stabilized zirconium oxide), the standard electrolyte for solid oxide fuel cells, due to its electric insulation properties and permeability for $\mathrm{O}^{2-}$ ions. $^{7}$

Atomic layer deposition (ALD), or in its general form chemical vapor deposition (CVD), has been already successfully applied for $\mathrm{ZrO}_{2}$. There are many precursor/oxidative agent pairs known to generate $\mathrm{ZrO}_{2}$ layers, ${ }^{8}$ with the main application as protection/coating layers. Applications beyond catalysis can also be found in microelectronics, where-prepared $\mathrm{ZrO}_{2}$ was used on $\mathrm{SiO}_{2}$ as an additional insulation layer. ${ }^{9}$ The synthesis of metallic $\mathrm{Zr}$ via the ALD/CVD pathway from metal-organic precursors to form, by sophisticated activation, nanoparticles 
for catalysis, has - to our knowledge - not been documented sufficiently. Due to the very high formation enthalpy of $\mathrm{ZrO}_{2}$, special preparation techniques for metallic $\mathrm{Zr}$ have been developed, ${ }^{10}$ with the aim to control problems of partial oxidation induced by the strong "getter" effect of $\mathrm{Zr}^{0}$. Therefore, CVD from zirconium-tert-butoxide (ZTB) was chosen in the present study as an easily applicable, reliable and effective way to prepare $\mathrm{ZrO}_{x} \mathrm{H}_{y}$ overlayers on Pd. The as-prepared CVD layers are not metallic, but contain partially oxidized and partially hydroxylated $\mathrm{Zr}^{4+}$ species, which nevertheless, can be easily reduced on $\mathrm{Pd}$ to $\mathrm{Zr}^{0}$ by means of an UHV-based posttreatment. Increased interest in $\mathrm{Zr}^{0}$-based pre-catalysts also arises from the fact, that oxidative segregation of initially bimetallic surfaces under reaction conditions was recently shown to yield active and selective inverse model catalysts. ${ }^{11}$ Such bimetallic pre-catalysts therefore represent a promising approach to obtain strongly enhanced activities (with respect to surface area) as compared to the related supported powder catalytic systems. The enhancement of surface-specific rates can be assigned to the extremely high number of metal-oxide phase boundary sites induced by localized oxidative segregation starting from an atomically dispersed alloy or intermetallic initial state. One of these examples is the initially bimetallic $\mathrm{Cu}-\mathrm{Zn}$ system. Starting from a dilute $\mathrm{Zn}-\mathrm{in}-\mathrm{Cu}$ alloy, finely dispersed zinc-(hydr)oxide islands are formed in situ, leading to a maximum of $\mathrm{Cu} / \mathrm{ZnO}_{x} \mathrm{H}_{y}$ phase boundary sites. ${ }^{12}$ Thus, an extremely active and selective "inverse" MSR catalyst is obtained. The same effect was shown for $\mathrm{Cu}-\mathrm{Zr}$, where metallic $\mathrm{Zr}$ was sputter-prepared on a $\mathrm{Cu}$ substrate and was oxidized/hydroxylated under MSR conditions, yielding phase boundary sites with equally improved $\mathrm{CO}_{2}$-selectivity and activity. ${ }^{11}$

Two distinct test reactions, methanol steam reforming and dry reforming of methane were chosen to investigate a potential co-catalytic and/or promotional function of surface-near $\mathrm{Zr}^{0}$-dopants on Pd. Although MSR is an efficient way to generate CO-depleted $\mathrm{H}_{2}$, catalyst stability issues and the required minimized CO content of the reformate gas make it still an intensely investigated reaction. ${ }^{4} \mathrm{Cu}$-based catalysts are known to be excellent to obtain high $\mathrm{CO}_{2}$-selectivity and high reaction rates ${ }^{12}$ but also Pd-based intermetallic systems are promising due to the methanol-activating function of $\mathrm{Pd}^{13}$ As a test reaction, MSR is useful to substantiate and quantify the lowtemperature water activation activity of the investigated catalyst systems, because of the fact that $\mathrm{CO}_{2}$ can only be formed via the reaction of activated methanol to formaldehyde, which further reacts with weakly bound $-\mathrm{OH}$ species from activated water toward $\mathrm{CO}_{2}$.

Dry reforming of methane (DRM) is a relevant reaction for the one-step conversion of two climate-relevant greenhouse gases, $\mathrm{CO}_{2}$ and $\mathrm{CH}_{4}$, to useful syngas. It is performed at higher temperatures ( $\sim 970 \mathrm{~K})$ than MSR and does not so much rely on initial water- but rather on $\mathrm{CO}_{2}$-activation. It is usually initiated by methane decomposition toward different carbon species. If the latter are sufficiently reactive, they can be further converted via the subsequent Boudouard reaction to $\mathrm{CO}$, or else, they remain deposited as unreactive coke. However, also the inverse water-gas-shift reactivity of the catalyst may play a role,${ }^{14}$ either as an additional intermediate process to generate water, which may be important for efficient gasification of carbon deposits, or as an unwanted side reaction reducing the $\mathrm{H}_{2}$ yield. Transition metals such as $\mathrm{Co}, \mathrm{Ni}, \mathrm{Ru}, \mathrm{Rh}, \mathrm{Ir}$ and $\mathrm{Pt}$ on alumina and silica supports ${ }^{15,16}$ have been reported as efficient DRM catalysts. Ceria as a support for $\mathrm{Ni}$ and Co was also applied, ${ }^{13}$ but also mixed ceria and zirconia supports. ${ }^{17}$ Clean Pd is known for its pronounced methane- but simultaneously quite poor $\mathrm{CO}_{2}$-activation ability. Therefore, DRM was chosen as a reference reaction to investigate the promotion of $\mathrm{CO}_{2}$ activation on a Zr-doped inverse Pd model catalyst, in order to highlight the role of the eventual initial $\mathrm{Zr}^{0}$ nanoclusters for enhanced $\mathrm{CO}_{2}$ activation.

The main goal of this inverse model catalyst study is therefore to highlight the co-catalytic/promotional role of redox-active $\mathrm{Zr}$ surface species on Pd beyond the simple function of zirconia as a structurally stabilizing catalyst support. As will be shown in the following, $\mathrm{Zr}^{0}$ clusters of 2-6 atoms adsorbed on Pd can be oxidized, reduced or hydroxylated reversibly at comparably low temperatures around $723 \mathrm{~K}$. Beyond the redox properties, electronic structure nano-effects of small particles and surface islands have also been described for other elements, i.e. gold on $\mathrm{TiO}_{2},{ }^{14,15,18,19}$ which may alter the catalytic properties substantially. $\mathrm{Zr}$, in its nanostructured highly redox-active surface-adsorbed state, is therefore investigated to be part of a potential redox active cycle and to open new reaction pathways on chemically and electronically altered Pd.

\section{Experimental and computational methods}

Depending on the experimental requirements, the research was performed using three experimental setups: An Omicron Surface Analysis Cluster (Birck Nanotechnology Center at Purdue University), an UHV-chamber with attached high-pressure recirculating batch reactor, and the Innovative Station for in situ Spectroscopy (Beamline ISISS at BESSY II synchrotron in Berlin).

\subsection{Omicron setup}

The Omicron Surface Analysis Cluster consists of a UHV preparation chamber and an analysis chamber with base pressures of $1 \times 10^{-9} \mathrm{mbar}$ and $5 \times 10^{-11} \mathrm{mbar}$, respectively. Samples can be transferred between these chambers under UHV. The preparation chamber is equipped with a mass spectrometer, an $\mathrm{Ar}^{+}$sputtering gun, a gas manifold system, and resistive sample heating. The analysis chamber is equipped with X-ray Photoelectron Spectroscopy (XPS) (electron energy analyzer - Omicron EAC 125 and analyzer controller - Omicron EAC 2000), Low Energy Electron Diffraction (LEED) (Omicron), High Resolution Electron Energy Loss Spectroscopy (HREELS) (ELS5000, LK Technologies), Scanning Tunneling Microscopy (STM) (Omicron ambient temperature UHV STM/AFM), and resistive sample heating. XPS data are acquired using a non-monochromatic $\mathrm{Mg} \mathrm{K} \alpha \mathrm{X}$-ray source $(h \nu=1253.6 \mathrm{eV})$ at $150 \mathrm{~W}$. High resolution spectra are recorded 
at the constant pass energy of $20 \mathrm{eV}$. Photoelectrons are ejected at a $45^{\circ}$ angle with respect to the surface normal.

$\operatorname{The} \operatorname{Pd}(111)$ single crystal (orientation accuracy $<0.1^{\circ}$, Princeton Scientific) is cleaned by several cycles of $\mathrm{Ar}^{+}$-sputtering $(1 \mathrm{kV}$, $2 \mu \mathrm{A}$ sample ground current) and annealing to $900-1000 \mathrm{~K}$ until no contaminations could be detected by XPS, STM and LEED. Well-ordered monoatomic steps are seen in STM. Due to the potential impact of radiation of the X-ray source on the sample topography/chemistry, STM studies are always done before XPS characterization. Sample heating is performed in the analysis chamber.

Zirconium(Iv) tert-butoxide $\mathrm{Zr}\left(\mathrm{O}-\mathrm{t}-\mathrm{C}_{4} \mathrm{H}_{9}\right)_{4}$ (Strem, purity: 99\%) is used as ALD/CVD precursor and filled into an cylinder under Ar. Prior to dosing ZTB, several cycles of freeze-pump-thaw are performed for purification (cooling temperature: $223 \mathrm{~K}$, freezing point ZTB: $269 \mathrm{~K}$ ). ZTB has a sufficient vapor pressure at room temperature to dose it directly through a leak-valve. Before sample exposure, the preparation chamber is exposed to the precursor at $5 \times 10^{-7}$ mbar for 5 minutes to passivate the chamber walls against precursor decomposition. The exposure is calculated from uncorrected ion gauge measurements in Langmuir, ( $1 \mathrm{~L}=1 \times 10^{-6}$ Torr s) involving exposure pressures in the range of $5 \times 10^{-8}$ to $5 \times 10^{-6} \mathrm{mbar}$. The adsorbate coverage is determined from XPS data (details can be found in the XPS experimental section or additionally in ref. 20-23).

\subsection{UHV-chamber with attached high-pressure recirculating batch reactor}

Sample preparation and characterization was performed in a combined preparation/analysis chamber with attached reaction cell, described in more detail elsewhere (base pressure in the low $10^{-9}$ mbar range). ${ }^{24}$ The sample is heated via a home-built e-bombardment setup. Electrons are ejected from a triplefilament emitter (operated with $30 \mathrm{~W}$ heating power) set to $-500 \mathrm{~V}$, while the sample is set to $+300 \mathrm{~V}$. The electron impact heating power is controlled via the filament emission current. For spectroscopic analysis, the chamber is equipped with a hemispherical electron and ion analyzer (Thermo Fisher Electron Alpha 110), a double anode X-ray gun for XPS (Mg/Al, XR 50, Specs), an ion gun sufficient to produce $1 \mathrm{kV} \mathrm{He}{ }^{+}$ions for ISS (Omicron 100) and an electron beam gun for Auger electron spectroscopy (KPI EGPS-2017B). Additionally, a mass spectrometer (Balzers) for residual gas analysis and $\mathrm{an}^{+}{ }^{+}$ion sputter gun for sample cleaning is attached. A three way gas inlet allows to dose $\mathrm{O}_{2}$ (Messer, 5.0), $\mathrm{H}_{2}$ (Messer 5.0) or $\mathrm{O}_{2}$ cleaned $\mathrm{Ar}$ (Messer 5.0) via leak valves into the chamber. All XPS spectra in this chamber are recorded with a non-monochromatic $\mathrm{Mg} \mathrm{K} \alpha$ $\mathrm{X}$-ray source $(h \nu=1253.6 \mathrm{eV})$ at $250 \mathrm{~W}$ and at the magic angle to the analyzer. For XPS the analyzer is operated at a constant pass energy of $20 \mathrm{eV}$.

All catalytic experiments are performed using a $20 \times 18 \mathrm{~mm}$ ultra-clean polycrystalline Pd foil (Goodfellow, 99.95\%) with a thickness of $0.125 \mathrm{~mm}$. For reference experiments on pure $\mathrm{ZrO}_{2}$, a pre-oxidized $0.127 \mathrm{~mm} \mathrm{Zr}$ foil with the same size (Alfa Aesar, purity: $99.95 \%$ ) is used. The foils are cleaned before loading to the UHV chamber in a water and an ethanol ultrasonic bath for
20 min, respectively. ZTB (Sigma Aldrich, purity. 99.999\%) is filled and mounted to the combined preparation/analysis chamber as described for the Omicron setup above. ZTB exposition is performed as described in the context of the individual experiments discussed below. Sample heating is performed by electron impact heating.

In order to validate the CVD-based catalytic results and to obtain a broader experimental basis of the $\mathrm{Pd}-\mathrm{Zr}^{0}$ system with respect to reforming performance, also an intermetallic bulk phase of $\mathrm{Pd}$ and $\mathrm{Zr}^{0}$ is prepared. The preparation is performed under HV conditions (base pressure $1 \times 10^{-7} \mathrm{mbar}$ ) by heating small pieces of the above-specified pure $\mathrm{Pd}$ and $\mathrm{Zr}$ foil samples resistively in a Ta crucible in the nominal atomic ratio $2: 1$. At a temperature slightly above the melting point of $\mathrm{Pd}(1828 \mathrm{~K})$, spontaneous reaction between $\mathrm{Pd}$ and $\mathrm{Zr}$ leads to an intermetallic Pd-Zr melt, which then recrystallizes toward Pd-Zr bulk phases during cooling in vacuum. Thereafter, this sample is transferred to the UHV system with attached batch reactor for analysis and catalytic testing. Note, that this sample, in comparison to the CVD-prepared ones, is exposed to air at room temperature between preparation and characterization. The nominal 2:1 Pd:Zr stoichiometry (i.e. with Pd excess) is chosen with the idea to maintain at least some active Pd metal surface coexisting with oxidatively segregated $\mathrm{Zr}$ species under reaction conditions. Moreover, an excess of Pd is necessary because the melting point of $\mathrm{Zr}$ is very high and complete intermetallic formation reaction of $\mathrm{Pd}$ with $\mathrm{Zr}$ is necessary in order to distribute the $\mathrm{Zr}^{0}$ homogeneously in the melt. The corresponding $\mathrm{X}$-ray diffraction patterns of the initial $\mathrm{Pd}-\mathrm{Zr}$ sample is made up by a complex superposition of at least two different $\mathrm{Pd}-\mathrm{Zr}$ intermetallic phases, including $\mathrm{Pd}_{3} \mathrm{Zr}$ and $\mathrm{Pd}_{4} \mathrm{Zr}_{3}$, alongside a small amount of oxidized monoclinic $\mathrm{ZrO}_{2}$. Note that this is in striking contrast to the similarly prepared $\mathrm{Cu}-\mathrm{Zr}$ samples, ${ }^{24}$ indicating a much less initial homogeneous melt. In due course, as will be discussed below, after the DRM reaction, the patterns are even more complicated, indicating phase transformations and partial (oxidative) decomposition of the intermetallic $\mathrm{Pd}-\mathrm{Zr}$ compounds.

For catalytic testing in the ambient pressure recirculating batch reaction cell, a long z-transfer rod allows fast and reliable transfer without exposure to air. The all-quartz-glass high-pressure (up to 1 bar) batch reactor is equipped with a gas chromatograph with either intermediate or continuous EID-MS detection to determine the exact gas composition at any point of reaction. Continuous partial pressure detection is performed via a capillary leak to the GC-MS. The quartz-glass reactor with a total circulation volume of $296 \mathrm{ml}$ is designed to measure small reaction rates and selectivity patterns within a temperature range between room temperature and $1300 \mathrm{~K}$. A circulation pump ensures a constant flow and gas intermixing and an attached gas-premixing unit allows to set arbitrary compositions of the attached reactant vapors or introduced gases (methanol, methane (5.0), deionized and degassed water, $\mathrm{CO}_{2}$ (5.0), $\mathrm{O}_{2}(5.0), \mathrm{H}_{2}$ (5.0), $\mathrm{Ar}$ (5.0) and $\mathrm{He}$ (5.0). The sample holder itself is entirely made of quartz glass to avoid background reactivity from hot metal parts and is designed for $20 \mathrm{~mm} \times 18 \mathrm{~mm}$ metal foils. 
A partial pressure of 8-30 mbar argon added to all gas mixtures allows to account for the thermal expansion due to the temperature increase and the simultaneous gas loss through the capillary leak for continuous EID-MS detection. For partial pressure calculations, all base-line-corrected MS signals are calibrated using pure substances with quantitative consideration of fragmentation. For all MSR catalytic experiments shown in this work, the following initial conditions are applied: 12 mbar methanol, 24 mbar water, 8 mbar argon, He added to a total pressure of 1 bar. After an equilibration and premixing period of $10 \mathrm{~min}$, a heating routine (rate $10 \mathrm{~K} \mathrm{~min}^{-1}$ ) up to $623 \mathrm{~K}$ is performed, followed by an isothermal period at 623 K. For all DRM catalytic experiments shown in this work, 50 mbar methane, 50 mbar $\mathrm{CO}_{2}, 30$ mbar Ar, adding He added to a total pressure of 1 bar were chosen. After an equilibration and premixing period of $10 \mathrm{~min}$, a temperature ramp up to $1073 \mathrm{~K}$ within $30 \mathrm{~min}$ was performed, followed by a corresponding isothermal period at $1073 \mathrm{~K}$. For discussion about mass and heat transport limitations, we refer to a thorough discussion of the catalytic setup in ref. 25 .

\subsection{In situ XPS setup}

Synchrotron-based in situ XPS experiments were performed at the ISISS (Innovative Station for in situ Spectroscopy) beamline at the BESSY II synchrotron in Berlin, Germany. The experimental apparatus consists of a load lock and an in situ cell connected to the XPS spectrometer via differential pumping stages. The experimental apparatus has been described in the literature in detail previously. ${ }^{26}$ Samples are heated in the in situ cell via a near-infrared semiconductor laser $(\lambda=808 \mathrm{~nm})$ from the rear. The temperature is measured by a K-type (chromelalumel) thermocouple positioned between sample holder back plate and Pd foil. All in situ experiments are performed on the same Pd foil sample that is used for the model catalyst preparation in the UHV instrument with attached batch reactor.

The same ZTB cylinder/leak valve setup described above is transferred to ISISS beamline. Due to the fact that ZTB only interacts with surfaces hotter than $500 \mathrm{~K}$, it is safe to dose the organometallic precursor into the analysis chamber without any $\mathrm{Zr}$ deposition on the components of the vacuum system or on the X-ray window. The growth of ZTB can then be followed directly via XPS. To determine a potential influence of the X-ray beam on the sample structure and chemistry, heating was performed at random checking with and without X-ray beam. As no distinct changes in the spectra between the two runs have been observed, this influence is considered to be marginal.

Monochromator control allows to chose photon energies corresponding to kinetic energies of the ejected photoelectrons of $120 \mathrm{eV}$ for all monitored core-level photoemission peaks in order to extract information from a constant information depth and to yield the same attenuation of the photoelectrons through the gas phase. Due to the fact that $95 \%$ of the signal arises from a sample depth up to $\sim 1 \mathrm{~nm}$, this operation mode is considered to be maximum "surface sensitive".

Photoelectrons are collected in the direction normal to the surface at constant pass energy of $10 \mathrm{eV}$. Binding energies were referenced to the Fermi edge, which is measured each time the monochromator moves to a new position (i.e. whenever the incident photon energy was changed). Photoemission peak intensities are corrected for the respective photon flux at a given photon energy. Since the BESSY II synchrotron operates in top-up mode (constant ring current), no additional correction for the ring current was required. Since all photoemission peaks were collected at the same kinetic energy of photoelectrons $(120 \mathrm{eV})$, the attenuation through the gas phase was the same for all-core levels and, thus, cancels out in coverage calculations.

\subsection{Analysis of the XPS data}

All spectra are analyzed using the CasaXPS software program, version 2.3.16 Pre-rel 1.4 (Casa Software Ltd). ${ }^{27}$ A Shirley background is applied to all spectra and the associated Scofield relative sensitivity factors are used for quantification. For peak fitting of the $\mathrm{Zr}$ 3d peaks a weighted sum of Gaussian and Lorenzian peak shapes (CasaXPS line shape SGL(30)) is assumed, using a doublet separation $\left(\mathrm{Zr} \mathrm{3d}_{5 / 2} v s\right.$. $\left.\mathrm{Zr} 3 \mathrm{~d}_{3 / 2}\right)$ of $2.4 \mathrm{eV}$ for both metallic $\mathrm{Zr}^{28}$ and zirconia ${ }^{29}$ was used for fitting. The doublet area is kept constant at 3:2 as arising from spin-orbit d-electron coupling. Electron attenuation lengths were taken from the NIST database SR $82^{30}$ and the orbital asymmetric parameter from the ELETTRA online database of ref. 31 The quantification of the XPS data is given as atomic percentages or coverage/thickness. The atomic percentage is estimated assuming homogeneously mixed elements. Since an adlayer on the substrate surface is not a homogeneous system, the coverage/thickness gives a better representation. The $\mathrm{ZrO}_{x} \mathrm{H}_{y}$ surface coverage is calculated assuming a non-attenuating adlayer on a semi-infinite substrate. ${ }^{20-23}$ As the maximum $\mathrm{ZrO}_{x} \mathrm{H}_{y}$ layer thicknesses remained in the sub-monolayer regime in this study, the influence of a potential attenuation effect of the photoelectrons by the overlayer remains negligible even for the highest exposures. This is tested by comparing the

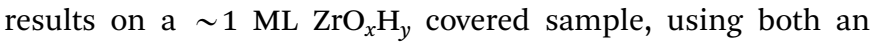
attenuating and non-attenuating overlayer model, which eventually shows negligible differences. Details of these calculations are given in ref. $20-23$ and in the ESI, $\dagger$ Section A.

\subsection{Density functional theory (DFT)}

All calculations are performed with plane-wave DFT using the Vienna $a b$ initio simulation package (VASP) using the projector augmented wave (PAW) method. ${ }^{32,33}$ To elucidate the role of the van der Waals interaction in this system, we perform vdW-DF calculations using the optB88 functional. ${ }^{34,35}$ The cutoff energy for the plane wave basis set is fixed at $400 \mathrm{eV}$. Geometry optimization is performed with a conjugate-gradient algorithm and considered to be converged when the forces on each unconstrained atom was $<0.01 \mathrm{eV} \AA^{-1}$. A Monkhorst-Pack grid of $2 \times 2 \times 1$ is employed due to the large unit cell. We use a $\sqrt{7} \times \sqrt{7}$ surface unit cell for $\operatorname{Pd}(111)$ with five layers thickness. The bottom two layers are fixed at their bulk position. On top of the Pd surface, 1 to 3 layers of a $(2 \times 2)$ cubic $\mathrm{ZrO}_{2}$ film are adsorbed and fully optimized. According to the previous 
experimental STM observations and theoretical work, ${ }^{16,17}$ we take the (111) surface of cubic $\mathrm{ZrO}_{2}$ as the surface orientation of the $\mathrm{ZrO}_{2}$ film. The calculated lattice mismatch between each other is $1.3 \%$. The reaction energy $\Delta E$ of deposited $\mathrm{ZrO}_{2}$ films on the Pd surface is calculated by

$$
\Delta E=\left[E_{\text {total }}\left(\mathrm{ZrO}_{2}-\mathrm{Pd}\right)-E_{\text {total }}\left(\mathrm{Pd}^{\text {surf }}\right)-n_{\mathrm{ZrO}_{2}} E_{\text {total }}\left(\mathrm{ZrO}_{2}^{\text {bulk }}\right)\right] / A_{\text {cell }}
$$

which is defined by the difference between the total energy of the compound system $\left[E_{\text {total }}\left(\mathrm{ZrO}_{2}-\mathrm{Pd}\right)\right]$ and the sum of the total energy of the clean Pd surface $\left[E_{\text {total }}\left(\mathrm{Pd}^{\text {surf }}\right)\right]$ and the total bulk energy $\left[E_{\text {total }}\left(\mathrm{ZrO}_{2}^{\text {bulk}}\right)\right]$ of as many $\mathrm{ZrO}_{2}$ formula units as are adsorbed within a unit cell on top of the metal surface $\left(n_{\mathrm{ZrO}_{2}}\right)$ divided by the area of the two-dimensional unit cell $A_{\text {cell }}$. The smaller the $\Delta E$ value, the more stable the structure becomes.

The formation energy of $\mathrm{ZrO}_{2}$ films with a different number of layers is defined by

$$
\Delta E_{\text {film }}=E_{\text {total }}\left(\mathrm{ZrO}_{2}\right)-n_{\mathrm{ZrO}_{2}} E_{\text {total }}\left(\mathrm{ZrO}_{2}^{\text {bulk }}\right)
$$

where $E_{\text {total }}\left(\mathrm{ZrO}_{2}\right)$ is the total energy of the relaxed $\mathrm{ZrO}_{2}$ film. Here the lattice parameters $(a=b)$ of the $\mathrm{ZrO}_{2}$ film and the ion positions are all allowed to change. The adsorption energy of the $\mathrm{ZrO}_{2}$ film at the $\mathrm{Pd}(111)$ surface is then calculated by

$$
\Delta E_{\text {ads }}=E_{\text {total }}\left(\mathrm{ZrO}_{2}-\mathrm{Pd}\right)-E_{\text {total }}\left(\mathrm{Pd}^{\text {surf }}\right)-E_{\text {total }}\left(\mathrm{ZrO}_{2}\right) .
$$

From eqn (1)-(3), it follows $\Delta E=\left(\Delta E_{\text {film }}+\Delta E_{\text {ads }}\right) / A_{\text {cell }}$.

The temperature- and pressure-dependent terms of condensed phases are small and tend to be neglected in the free energy calculation. The differences between the chemical potentials can be approximated by the difference between their calculated DFT electronic energies ( $\left.E_{\text {total }}\right)$. For the gas phase, the thermal contributions from the translational, rotational and vibrational enthalpies and entropies are added. ${ }^{36}$ By this definition, the reaction energy $\Delta G_{\text {diss }}$ for oxygen dissolution into Pd sub-layer and $\Delta G_{\text {diff }}$ for oxygen diffusion to the available bare $\operatorname{Pd}(111)$ surface are not affected by the reaction temperature and pressure, and will be equal to the reaction energy at $0 \mathrm{~K}$.

The reaction energy $\Delta G_{\text {diss }}$ for oxygen dissolution into $\mathrm{Pd}$ sub-layer is calculated by

$$
\Delta G_{\text {diss }}=E_{\text {total }}\left(\mathrm{ZrO}_{2}-\mathrm{O}-\mathrm{Pd}\right)-E_{\text {total }}\left(\mathrm{ZrO}_{2}-\mathrm{Pd}\right) .
$$

$E_{\text {total }}\left(\mathrm{ZrO}_{2}-\mathrm{O}-\mathrm{Pd}\right)$ is the total energy of $\mathrm{ZrO}_{2}-\mathrm{Pd}$ system with one oxygen dissolving into the $\mathrm{Pd}$ sub-layer. The reaction energy $\Delta G_{\text {diff }}$ for oxygen diffusion to the available neighboring bare $\operatorname{Pd}(111)$ surface is then calculated by

$$
\begin{aligned}
\Delta G_{\text {diff }}= & E_{\text {total }}\left[\left(\mathrm{ZrO}_{2}\right)_{\text {Ovacancy }}-\mathrm{Pd}\right]+E_{\text {total }}(\mathrm{O}-\mathrm{Pd}) \\
& -E_{\text {total }}\left(\mathrm{ZrO}_{2}-\mathrm{Pd}\right)-E_{\text {total }}\left(\mathrm{Pd}^{\text {surf }}\right) .
\end{aligned}
$$

$E_{\text {total }}\left[\left(\mathrm{ZrO}_{2}\right)_{\text {Ovacancy }}-\mathrm{Pd}\right]$ is the total energy of the compound $\mathrm{ZrO}_{2}-\mathrm{Pd}$ system with one oxygen vacancy at the $\mathrm{ZrO}_{2}$ film. $E_{\text {total }}(\mathrm{O}-\mathrm{Pd})$ is the total energy of the $\mathrm{Pd}(111)$ surface with one adsorbed oxygen atom. All the Pd surfaces here have the same surface area. For the $\mathrm{O}_{2}$ production in the gas phase, the reaction Gibbs free energy $\Delta G_{\mathrm{O}_{2}}$ is calculated by

$$
\Delta G_{\mathrm{O}_{2}}=\Delta E_{0}+0.5 G(T)
$$

with

$$
\Delta E_{0}=E_{\text {total }}\left[\left(\mathrm{ZrO}_{2}\right)_{\text {Ovacancy }}-\mathrm{Pd}\right]+0.5 E_{\text {total }}\left(\mathrm{O}_{2}\right)-E_{\text {total }}\left(\mathrm{ZrO}_{2}-\mathrm{Pd}\right) .
$$

$\Delta E_{0}$ is the reaction energy at $0 \mathrm{~K}$ including the zero-point energy evaluating from the difference of the electronic energies between the products and the reactants, and $G(T)$ represents the free energy of $\mathrm{O}_{2}$ in the gas phase under the chosen experimental reaction temperature and pressure. $E_{\text {total }}\left[\left(\mathrm{ZrO}_{2}\right)_{\text {Ovacancy }}-\mathrm{Pd}\right]$ is the total energy of the compound $\mathrm{ZrO}_{2}-\mathrm{Pd}$ system with one oxygen vacancy at the $\mathrm{ZrO}_{2}$ film.

\section{Results}

\subsection{Synthesis of the starting catalyst structure and redox chemistry of $\mathrm{Zr}$}

3.1.1. ZTB adsorption on palladium surfaces and the ALD/ CVD window. Following ZTB exposure of $\operatorname{Pd}(111)$ at room temperature, only a small amount of zirconium is detected by XPS and only when $\operatorname{Pd}(111)$ is pre-treated with oxygen prior to ZTB exposure $\left(2000 \mathrm{~L}\right.$ at $298 \mathrm{~K}$; this yields a $\mathrm{p}(2 \times 2) \mathrm{O}_{\text {ads }} / \mathrm{Pd}(111)$ structure, but no surface Pd oxide, which only forms at elevated temperatures). The coverage of as-deposited $\mathrm{ZrO}_{x} \mathrm{H}_{y}$ is estimated to be in the range of $10^{-2} \mathrm{ML}$ following high exposures of $\sim 2000 \mathrm{~L}$. In order to increase the $\mathrm{ZrO}_{x} \mathrm{H}_{y}$ coverage, we explore an ALD-like approach: multi-cycles of ZTB exposure followed by annealing in UHV. ZTB exposure is performed at room temperature the (first half of the ALD cycle) and annealing in UHV is performed at $673 \mathrm{~K}$ (second half of the ALD cycle, no co-reactant). As shown in Fig. 1A, this approach does not help to grow more $\mathrm{Zr}$ : no increase of the $\mathrm{Zr}$ amount is observed with number of cycles. The carbon coverage is in the range of $\sim 1.5 \mathrm{ML}$, increasing after ZTB exposure and decreasing after UHV annealing, which also results in removing Zr.

Typically, an ALD/CVD process is characterized by a specific temperature window. For instance, the exposure temperature is recommended to be around $650 \mathrm{~K}$ for $\mathrm{Si}^{9}{ }^{9}$ The ALD window for the decomposition of ZTB on a $\mathrm{SiO}_{2}$ wafer was between $573 \mathrm{~K}$ and $673 \mathrm{~K} \cdot{ }^{37,38}$ The activation barrier was explained by a hydride elimination step, which was considered as a rate limiting step, and the formation of isobutene. ${ }^{37}$ A pure ALD mechanism was supposed to occur below $573 \mathrm{~K}$. We investigated the dependence of the zirconium amount from the ZTB exposure temperature. Fig. 1B shows the amount of zirconium and carbon (in atomic percent for a rough quantitative estimation) calculated from the $\mathrm{Zr} 3 \mathrm{~d}$ and $\mathrm{C}$ 1s XPS peaks as a function of ZTB exposure temperature. Carbon can be mainly found on the surface following exposure at temperatures below a sharp threshold of $\sim 573 \mathrm{~K}$. Above $573 \mathrm{~K}$, the $\mathrm{Zr} / \mathrm{Pd}$ ratio increases rapidly and the amount of carbon decreases. A remarkably similar behavior was observed during $\mathrm{ZrO}_{2}$ growth from ZTB on $\mathrm{Si}(100)$ by Cameron and George, ${ }^{38}$ where the CVD rate of $\mathrm{ZrO}_{2}$ increased sharply above $573 \mathrm{~K}$ and then started to drop above $773 \mathrm{~K}$. At high temperatures, $\mathrm{ZrO}_{2}$ deposition was supposed to be partially poisoned by carbon. Fourier transform infrared spectroscopy (FTIR) demonstrated hydroxyl $\left(\mathrm{ZrOH}^{*}\right)$ and butoxide 

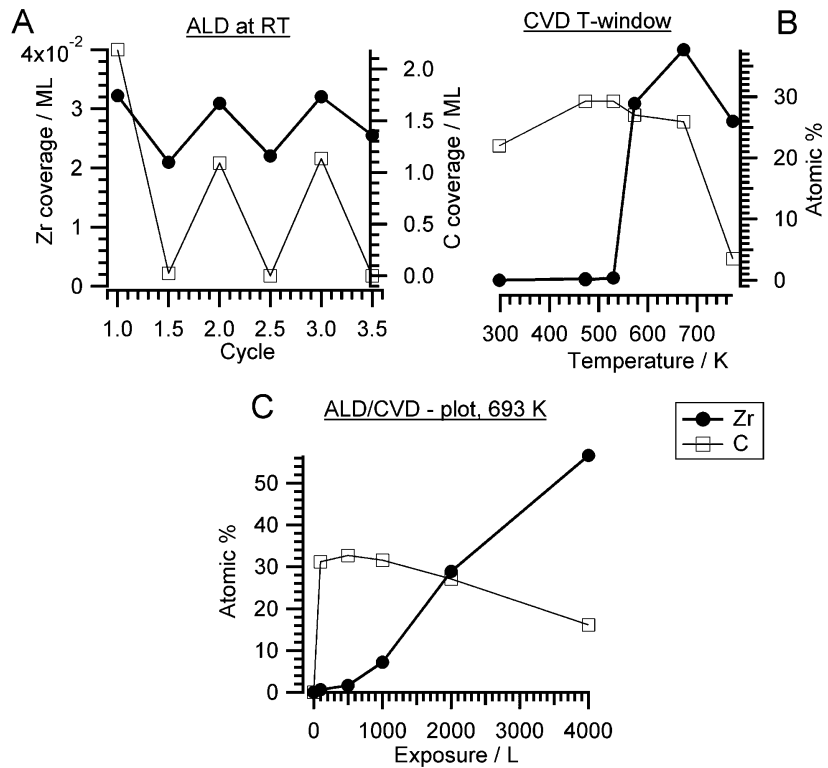

Exposure / $\mathrm{L}$

Fig. 1 (A) $\mathrm{Zr}$ and $\mathrm{C}$ coverage as a function of number of ALD-like cycles: 1st half cycle - 2000 L ZTB adsorption at RT and 2nd half cycle annealing at $673 \mathrm{~K}$ in vacuum. Prior to the first ALD cycle, the clean $\mathrm{Pd}$ (111) surface was exposed to $2000 \mathrm{~L} \mathrm{O}_{2}$ at $298 \mathrm{~K}$; (B) constant exposure of $2000 \mathrm{~L}$ at selected temperatures, indicating the CVD window. (C) Langmuir plot of $\mathrm{Zr}$ and $\mathrm{C}$ atomic\% derived from $\mathrm{Zr} 3 \mathrm{~d}, \mathrm{C}$ 1s and $\mathrm{Pd} 3 \mathrm{~d}$ versus ZTB exposure at $693 \mathrm{~K}$ (isothermal conditions).

$\left(\mathrm{ZrOC}\left(\mathrm{CH}_{3}\right)_{3}{ }^{*}\right)$ species on $\mathrm{ZrO}_{2}$, whose concentration decreased roughly linearly with temperature from $300-800 \mathrm{~K} \cdot{ }^{33}$ In our case, we do not detect much carbon deposition at high temperatures. However, a much lower ZTB pressure is used in our study $\left(\sim 10^{-5}\right.$ Torr vs. 0.05 Torr in ref. 38) and Pd exhibits a high carbon dissolution capability. ${ }^{39}$ Therefore, on Pd the amount of deposited $\mathrm{Zr}$ decreases above $673 \mathrm{~K}$ most likely due to kinetic limitations: fast desorption of ZTB effectively competes with dissociation. The temperatures between $550-773 \mathrm{~K}$ are most efficient for zirconium deposition, more effective than multiple ALD-like cycles at room temperature. The temperature of $693 \mathrm{~K}$ is usually used for the CVD experiments described in this study because of the empirically determined trade-off between reducing the unwanted carbon deposition and optimizing the $\mathrm{Zr}$ amount.

A Langmuir-type plot (deposited amount of $\mathrm{Zr}$ and $\mathrm{C}$ versus ZTB exposure in Langmuir) obtained at $673 \mathrm{~K}$ is shown in Fig. 1C. No zirconium saturation was observed even at $4000 \mathrm{~L}$, while the carbon amount was decreasing with exposure. Increasing with exposure, the $\mathrm{Zr}$ amount is more typical for CVD than for ALD. The CVD was also reported for ZTB adsorption on $\mathrm{Si}(100) \cdot{ }^{38}$ Interestingly, carbon is displaced by zirconium compounds, which might reflect a competition for adsorption/ dissociation sites between ZTB and its decomposition products (i.e. hydrocarbons). ZTB dissociation products could hinder ZTB adsorption and block further ZTB dissociation. A similar situation was observed during trimethylaluminum and ferrocene adsorption on $\mathrm{Pd}(111)$ and $\mathrm{Pt}(111))^{21,22}$ The CVD growth of $\mathrm{ZrO}_{x} \mathrm{H}_{y}$ on $\mathrm{Cu}$ is also monitored in situ. The corresponding XP spectra are shown in the ESI $\dagger$ in Fig. S1.

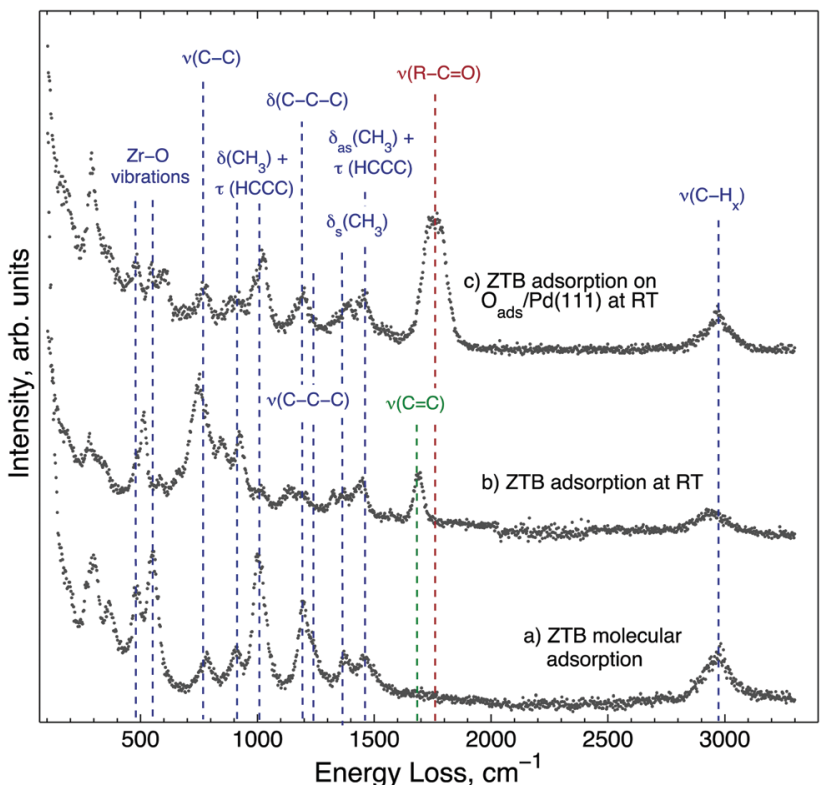

Fig. 2 HREEL spectra obtained following $2000 \mathrm{~L}$ ZTB exposure of the $\mathrm{Pd}(111)$ surface (a) at $180 \mathrm{~K}$ and heated to $293 \mathrm{~K}$ in UHV, (b) and (c) at $293 \mathrm{~K}$; for (c), $\mathrm{Pd}(111)$ was pre-exposed to $2000 \mathrm{~L} \mathrm{O}_{2}$ at $673 \mathrm{~K}$. HREELS spectra were collected at $293 \mathrm{~K}$. The energy losses, which are characteristic of ZTB, are marked in blue.

In order to identify adsorption species and to understand the low zirconium uptake below $550 \mathrm{~K}$, ZTB adsorption is investigated by HREELS (Fig. 2). Molecularly adsorbed ZTB was prepared by $2000 \mathrm{~L}$ exposure on $\operatorname{Pd}(111)$ at $180 \mathrm{~K}$ and followed by warming up to $293 \mathrm{~K}$ (spectrum (a) in Fig. 2). Despite the rather complex spectrum, all detected vibrations are very similar to those detected from FTIR in gas phase for the tert-butyl group and ZTB. ${ }^{40-43}$ In XPS (ESI, $\dagger$ Fig. S2), two separate C 1s peaks can be seen at $286.9 \mathrm{eV}$ and $284.9 \mathrm{eV}$ following ZTB exposure, which can be attributed to carbon bound to oxygen or carbon, respectively. By comparison with the $\mathrm{Zr} 3 \mathrm{~d}_{5 / 2}$ peak area, the $\mathrm{C} / \mathrm{Zr}$ ratios for the oxygenated and non-oxygenated species are 4.9 and 17.4, respectively. This allows us to conclude that adsorption of ZTB is mostly molecular under these conditions. The characteristic frequencies of ZTB on Pd(111) are summarized in the ESI $\dagger$ in Table S2 and compared with literature values. The HREELS spectrum obtained following ZTB adsorption on Pd(111) at $293 \mathrm{~K}$ (spectrum (b) in Fig. 2) is slightly different. The main difference is a new peak at $1685 \mathrm{~cm}^{-1}$ (marked dark-green). This peak can be assigned to the stretching of the double $\mathrm{C}=\mathrm{C}$ bond ${ }^{44-46}$ which most likely is due to adsorbed isobutylene species. Indeed, thermal desorption of isobutylene correlated with the $\mathrm{ZrO}_{2}$ growth rate, ${ }^{38}$ and this observation along with FT-IR-detected butoxide species $\left(\mathrm{ZrOC}\left(\mathrm{CH}_{3}\right)_{3, \text { ads }}\right.$ ) allowed Cameron and George ${ }^{38}$ to conclude that the butoxide species decomposition via $\beta$-hydride elimination is the rate-limiting step for $\mathrm{ZrO}_{2}$ film growth. This conclusion is consistent with our HREELS data showing dissociation of ZTB and the appearance of the adsorbed isobutylene species. The intensity enhancement of a skeletal vibration of tert-butyl group, $\nu(\mathrm{C}-\mathrm{C})$, at $780 \mathrm{~cm}^{-1}$ infers 
that the surface is covered with ZTB dissociation products. The $\mathrm{C} / \mathrm{Zr}$ ratio increased compared to the molecular adsorption as well. The ratio for the room temperature-exposure roughly is 30:1 atomic\% $\mathrm{C}: \mathrm{Zr}$. Thus, hydrocarbon products of ZTB dissociation "passivate" the $\operatorname{Pd}(111)$ surface against further ZTB adsorption.

Spectrum (c) in Fig. 2 was obtained following $2000 \mathrm{~L} \mathrm{ZTB}$ exposure of $\mathrm{Pd}(111)$ covered by $\mathrm{O}_{\text {ads }}$. Interestingly, the spectrum is close to the one for the molecular adsorption of ZTB (spectrum (a), Fig. 2): it is likely that the surface contains less ZTB dissociation products, as no adsorbed isobutylene species are found on the surface. On the other hand, a new peak appeared at $1745-1775 \mathrm{~cm}^{-1}$ (dark-red), which can be due to a C-O stretching vibration in aldehyde or ketones. ${ }^{44-46}$ Likely, an isobutyl fragment splitting off ZTB could attach to a surface oxygen center without $\beta$-hydride elimination. No $\mathrm{OH}$ vibration following ZTB adsorption in all three cases is observed.

According to the HREELS data, even slight heating of ZTB adlayers in UHV resulted in decomposition of hydrocarbon species (ESI, $\dagger$ Fig. S3). Structure-wise, following adsorption of $100 \mathrm{~L} \mathrm{ZTB}$ at $673 \mathrm{~K}$, the surface is covered with a layer of rather disordered $\mathrm{ZrO}_{x}$ mixed with carbon as determined from STM images (Fig. 3A). This layer is not uniform and contains holes and cracks (Fig. 3B). The surface carbon species seen in this stage are most likely $\mathrm{C}_{x} \mathrm{H}_{y}$ fragments and/or graphitic deposits, as deduced from the main $\mathrm{C} 1 \mathrm{~s}$ components around $284 \mathrm{eV}$ (not shown). A relatively broad height distribution within the terraces (not shown) indicates the limited uniformity of the overlayer.

Based on the data discussed above, we propose the following mechanism of ZTB-Pd surface interaction.

On clean $\operatorname{Pd}(111)$, ZTB dissociates via $\beta$-hydride elimination, resulting in adsorbed isobutylene and butoxide $\left(\mathrm{ZrOC}\left(\mathrm{CH}_{3}\right)_{3, \text { ads }}\right)$ species. Isobutylene species either desorb as isobutylene or decompose and hydrogenate leaving carbon on the surface.
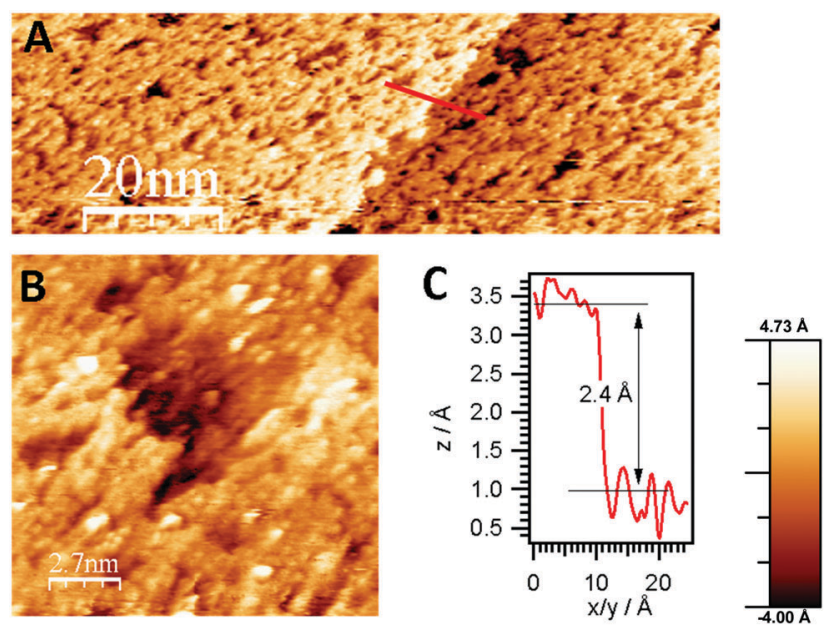

Fig. 3 (A) STM images of the CVD-grown $\mathrm{ZrO}_{x}$ overlayer on $\mathrm{Pd}(111)$ (100 L ZTB at $673 \mathrm{~K}, \mathrm{ZrO}_{x} \mathrm{H}_{y}$-carbon layer coverage estimated to $\sim 1 \mathrm{ML}$, bias voltage: $-0.8 \mathrm{~V}$, tunneling current: $0.4 \mathrm{nA}$ ), including monoatomic step edge profile in the $\mathrm{Pd}(111)$ surface, $(\mathrm{B})$ crack in the non-uniform mixed $\mathrm{ZrO}_{x} \mathrm{H}_{y}+$ carbon overlayer, C) height profile of step edge along the line shown in A.
The adsorbed butoxide species dissociates further, resulting in $\mathrm{ZrO}_{x}$ deposition (* denoting an adsorption site, $n$ and $x$ are stoichiometric factors):

$$
\begin{array}{r}
\mathrm{Zr}\left(\mathrm{OC}_{4} \mathrm{H}_{9}\right)_{4}+n^{*} \rightarrow \mathrm{Zr}\left(\mathrm{OC}\left(\mathrm{CH}_{3}\right)_{3}\right)_{x, \text { ads }}+(4-x) \mathrm{CH}_{2}=\mathrm{CH}-\left(\mathrm{CH}_{3}\right)_{2, \text { ads }} \\
+(4-x) \mathrm{O}_{\text {ads }} \quad(x=1,2 \text { and } n=7,5)
\end{array}
$$

As dissolution of carbon atoms in Pd is fast above $573 \mathrm{~K}$ on $\mathrm{Pd},{ }^{39}$ we assume this process to dominate the ALD vacuum annealing step. Some oxygen could be consumed for hydrogen and carbon oxidation. The further fate of $\mathrm{ZrO}_{2}$ is discussed separately. We can conclude that at temperatures below the threshold of $\sim 550 \mathrm{~K}$, the surface is poisoned by carbon compounds and above $773 \mathrm{~K}$, the deposition rate starts to decline due to kinetic limitations (too fast desorption of ZTB).

On $\mathrm{O}_{\text {ads }} / \mathrm{Pd}(111)$, the main difference is the appearance of alkoxide-like species showing $\mathrm{C}=\mathrm{O}$ stretching vibrations. The exact configuration of this species is out of this work's scope and would require further investigation.

3.1.2. Reduction and oxidation of Zr-containing species on Pd surfaces. Annealing in vacuum at $673 \mathrm{~K}$ removes carbon efficiently (structure Fig. 4, XP spectra shown in Fig. 5). Surprisingly, annealing for $10 \mathrm{~min}$ results in zirconium reduction to $\mathrm{Zr}^{0}$ : the $\mathrm{Zr} 3 \mathrm{~d}_{5 / 2}$ peak shifts from $183.15 \mathrm{eV}$ for the precursor $\left(\mathrm{Zr}^{4+}\right)$ to $179.6 \mathrm{eV}$, which is formally $\mathrm{Zr}^{0}$. This is a remarkable finding, since bulk zirconia is a very stable oxide and the reduction of bulk phases of this oxide without intimate contact to a noble metal is only possible under extremely harsh conditions. The oxide formation enthalpy is $-1100 \mathrm{~kJ} \mathrm{~mol}^{-1} \cdot{ }^{47} \mathrm{In}$ fact, it is usually very hard to even keep $\mathrm{Zr}$ in its metallic state. Fig. 4 shows the STM images obtained following $100 \mathrm{~L}$ ZTB exposure of $\mathrm{Pd}(111)$ at $673 \mathrm{~K}$ and annealing in UHV at $723 \mathrm{~K}$. According to XPS, carbon is largely removed, and STM detects evenly-distributed sub-nanometer clusters with the height of $\sim 0.4 \mathrm{~nm}$, corresponding to a monoatomic height step of zirconium. Note that in the images, most likely a double tip along the scan direction is present, which doubles the present Zr atom clusters. However, the 1-3 atom clusters (blue framed) were assigned to metallic $\mathrm{Zr}$. The atom-atom distance between two neighbouring elemental $\mathrm{Zr}^{0}$ atoms not being affected by the double tip amounts to $0.32 \mathrm{~nm}$ (hcp lattice), and does, thus, fit to a certain degree to the dimensions of the Pd arrangement of the Pd(111) surface, exhibiting a Pd-Pd distance of $0.28 \mathrm{~nm}$ between nearest neighboring atoms. The large misfit of the interatomic distances for $\operatorname{Pd}(111)$ and $\operatorname{Zr}(0001)$ likely prevents epitaxial growth of $\mathrm{Zr}$ on $\mathrm{Pd}(111)$.

The unusual behavior on Pd under vacuum conditions, leading to the formation of nanostructured $\mathrm{Zr}^{0}$ islands, is explained by efficient removal of oxygen atoms and an extremely low re-oxidation rate. As deduced from STM images and DFT 

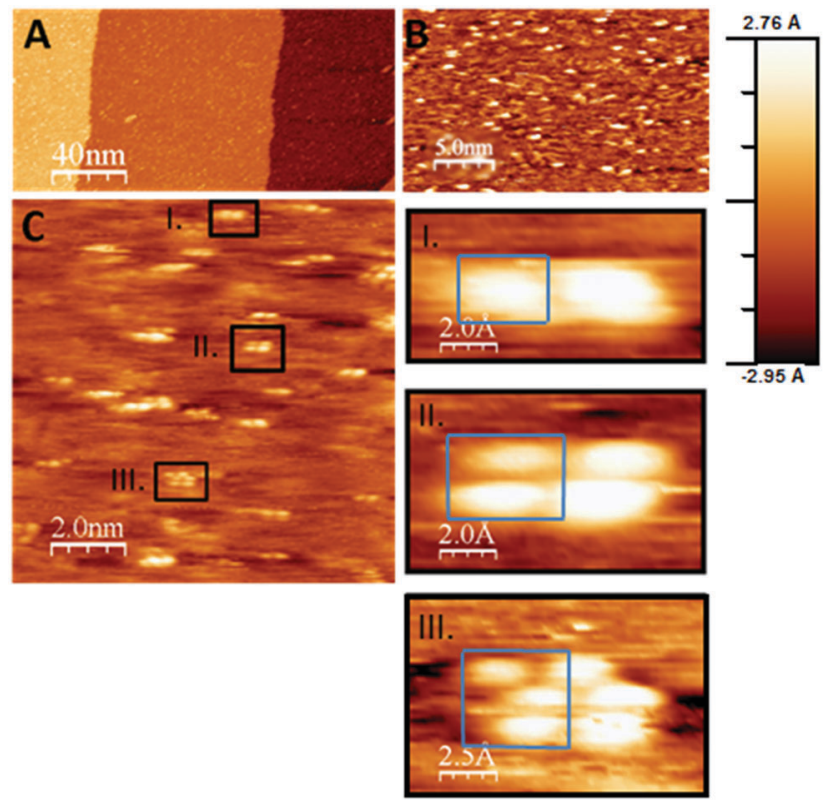

Fig. 4 (A-C) STM images obtained after CVD growth of the $\mathrm{ZrO}_{x} \mathrm{H}_{y}+\mathrm{C}$ overlayer (100 L ZTB at $673 \mathrm{~K}$ ) on $\mathrm{Pd}(111)$ followed by UHV-annealing to $723 \mathrm{~K}$ in $5 \times 10^{-11} \mathrm{mbar}$. The resulting $\mathrm{Zr}^{0}$ coverage was $\sim 0.1 \mathrm{ML}$, and no more carbon was detected after annealing. The formed $\mathrm{Zr}$-nanoclusters are shown in panel $C$ and sub-panels I-III. (gap voltage: $0.2 \mathrm{~V}$, constant current mode, feedback setting: $0.2 \mathrm{nA}$ ). Clusters containing 1-3 $\mathrm{Zr}$ atoms (blue frames) are seen (note that the structure most likely is imaged using a double tip. However, as all structural features seem to be doubled along the scan direction, the clusters containing 1-3 $\mathrm{Zr}$ atoms seen along the direction almost perpendicular to it are true $\mathrm{Zr}$ clusters being present on the surface).

calculations shown later, metal support interaction effects are also highly beneficial. Even though a number of Pd-Zr intermetallic bulk phases and/or compounds of varying stoichiometry are known, ${ }^{47,48}$ no such $\mathrm{Pd}-\mathrm{Zr}$ phases can be formed at temperatures as low as $673 \mathrm{~K}$. The $\mathrm{Zr}^{0}$ metallic surface state was confirmed on the Pd(111) surface by (i) almost no shift of the Pd $3 d_{5 / 2}$ peak (peak position: $335.2 \mathrm{eV}$ ) and (ii) the fact that the $\mathrm{Zr} 3 \mathrm{~d}$ intensity does not change following annealing (neither dissolution nor evaporation) and (iii) the shift of the $\mathrm{Zr} \mathrm{3d}$ binding energy toward $179.4 \mathrm{eV}$ typical for metallic $\mathrm{Zr}$ species. ${ }^{49,50}$ On the other hand, the interface between $\mathrm{ZrO}_{x}$ and the noble metal (Pd or Pt) likely plays an important role since this reduction is only working on Pd and Pt, but e.g. not on $\mathrm{Cu}$, which is a less active material.

In order to extend our understanding of ZTB CVD under UHV to more realistic conditions, we compare the UHV results to the in situ XPS data obtained at the synchrotron radiation facility BESSY-II. Fig. 5 shows the $\mathrm{Zr} 3 \mathrm{~d}$ spectra obtained during the in vacuo heating of the CVD grown $\mathrm{ZrO}_{x}$ film $(\sim 2000 \mathrm{~L}$ ZTB at $673 \mathrm{~K}$, deposited amount $\sim 0.6 \mathrm{ML})$ on $\operatorname{Pd}(111)$ and on polycrystalline Pd foil by the UHV-XPS (Omicron) and in situ by the NAP-XPS at BESSY II, respectively. The better vacuum conditions in the UHV-XPS set-up $\left(5 \times 10^{-11} \mathrm{mbar}\right.$, water free $)$ compared with the $5 \times 10^{-8}$ mbar water-containing background in the NAP-XPS chamber allowed to obtain completely

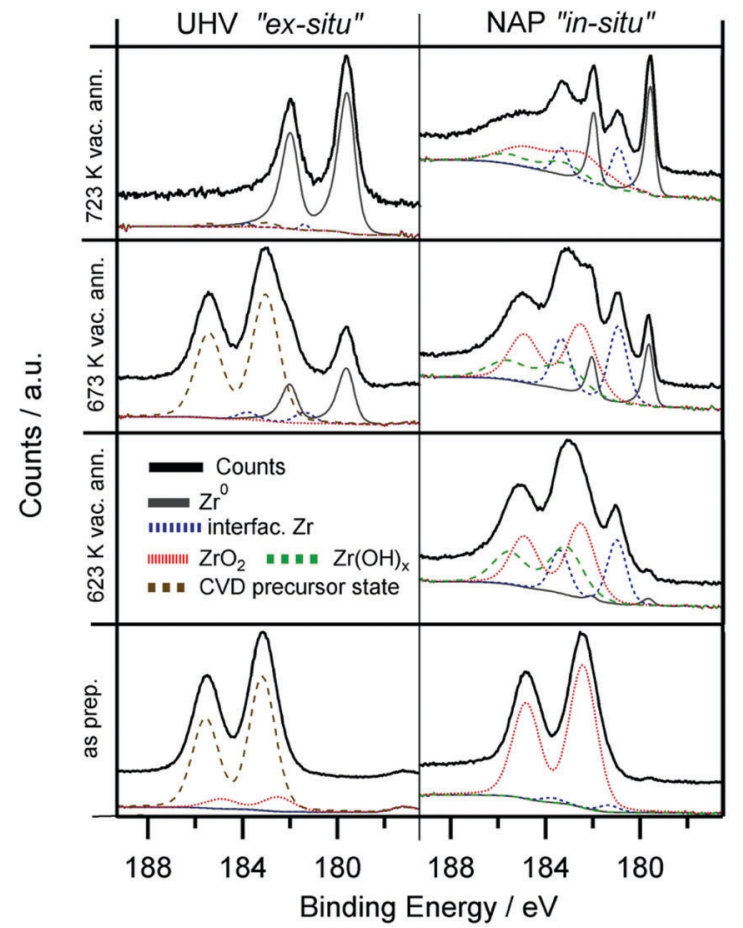

Fig. $5 \mathrm{Zr} 3 \mathrm{~d}$ spectra of the CVD-grown $\mathrm{ZrO}_{x} \mathrm{H}_{y}$ overlayer $(673 \mathrm{~K}, 2000 \mathrm{~L}$ $Z T B$ ) at room temperature ("as prepared") and after annealing in vacuum to $623 \mathrm{~K}, 673 \mathrm{~K}$ and $723 \mathrm{~K}$. Left panels: experiments on $\mathrm{Pd}(111)$, base pressure of the UHV XPS chamber $5 \times 10^{-11} \mathrm{mbar}$. Right panels: experiments on a Pd foil at the NAP-XPS setup of ISISS beamline at HZB/BESSY II, base pressure $5 \times 10^{-8} \mathrm{mbar}$. The initial $\mathrm{Zr}$ coverage for both experiments is approximately $0.6 \mathrm{ML}$.

reduced zirconium. In in situ NAP-XPS, the highly reactive ZTB precursor was converted to mainly $\mathrm{ZrO}_{2}$ right after preparation $\left({\mathrm{Zr} 3 \mathrm{~d}_{5 / 2}}\right.$ at $\left.182.4 \mathrm{eV}\right)$. Also the amount of carbon is significantly lower in UHV-XPS, which we assign to enhanced precursor decomposition due to the intense synchrotron beam of the in situ experiment and partially to the high base pressure. In both experiments, heating in vacuum results in reduction: only metallic $\mathrm{Zr}(179.4 \mathrm{eV})$ was detected in UHV-XPS, whereas a larger fraction of "partially reduced" zirconium (interfacial species) is additionally observed in the in situ NAP-XPS experiment, as a $\mathrm{Zr} 3 \mathrm{~d}_{5 / 2}$ component is found at $c a .181 .0 \mathrm{eV}$. This state is assigned to an ultrathin layer of $\mathrm{ZrO}_{2} \cdot{ }^{49}$ We tentatively assign this peak to oxygen-deficient and not fully metallic interfacial $\mathrm{ZrO}_{x} \mathrm{H}_{y}$, e.g. with metal-metal bonds to the $\mathrm{Pd}$ substrate and still remaining $\mathrm{Zr}-\mathrm{O}-\mathrm{Zr}$ entities to the outermost $\mathrm{ZrO}_{2}$ layer(s). This may explain the suggested oxidation state between $\mathrm{Zr}^{4+}$ and $\mathrm{Zr}^{0}$, but rather if e.g. a bi- or multilayered precursor would be affected by loss of interfacial oxygen between $\mathrm{Zr}$ and Pd.

The reduction of $\mathrm{Zr}^{4+}$ is more difficult in the NAP-XPSSystem, as not all $\mathrm{Zr}$ can be fully reduced to the metallic state (Fig. 5). In the ex situ UHV experiment, where the reduction is fast and complete, no such partially reduced intermediates could be detected. This difference most likely arises from the much poorer vacuum conditions of the in situ NAP-XPS chamber as discussed above. The background pressure of any oxygen 
containing molecules was, thus, found to be crucial for the eventual efficiency of $\mathrm{Zr}$ reduction. Also, the growth mode of the $\mathrm{Zr}^{4+}$ precursor species (i.e. layer thickness or island formation) may be already pre-determined by the residual gas conditions during deposition and/or annealing.

Upon further annealing ( $T>780 \mathrm{~K}$ ), dissolution of $\mathrm{Zr}$ into the Pd bulk occurs, leading to a significant loss of the $\mathrm{Zr} 3 \mathrm{~d}$ intensity and the formation of a near-surface $\mathrm{Pd}-\mathrm{Zr}$ alloy, as indicated by a slightly higher BE shift of the Pd 3d peaks (not shown herein). The $\mathrm{BE}$ of the dissolving $\mathrm{Zr}$ is found to be 179.6 eV, which is shifted about $0.2-0.4 \mathrm{eV}$ towards higher $\mathrm{BE}$ from the position for bulk $\mathrm{Zr}^{0}{ }^{50}$ The most likely reason is the enhanced Pd-Zr coordination in the subsurface regions, but charge-transfer processes and final state effects might also play a role.

3.1.3. Hydroxylation of surface $\mathrm{Zr}^{\mathbf{0}}$ species using water. The reduced state of $\mathrm{Zr}$ is heated to $723 \mathrm{~K}$ in $5 \times 10^{-6}$ mbar and 0.3 mbar $\mathrm{H}_{2} \mathrm{O}$ in the ex situ experiments and the in situ experiments, respectively. Hydroxylated zirconia, $\mathrm{ZrO}_{x} \mathrm{H}_{y}$, (Fig. 6, binding energy $\mathrm{Zr} 3 \mathrm{~d}_{5 / 2} \sim 183.0 \mathrm{eV}$ ) and also a minor $\mathrm{ZrO}_{2}$ component are detected in both experiments. In $5 \times 10^{-6} \mathrm{mbar}$ $\mathrm{H}_{2} \mathrm{O}$, the hydroxylation process is obviously slower because of a much lower $\mathrm{H}_{2} \mathrm{O}$ pressure. At $723 \mathrm{~K}$, hydroxylation mostly occurs within $15 \mathrm{~min}$ : the state assigned to interfacial $\mathrm{Zr}$ could be detected. Almost complete loss of $\mathrm{Zr}^{0}$ and the associated highest degree of hydroxylation is reached after $30 \mathrm{~min}$. Hydroxylation is faster and more complete in the in situ experiment ( 0.3 mbar) due

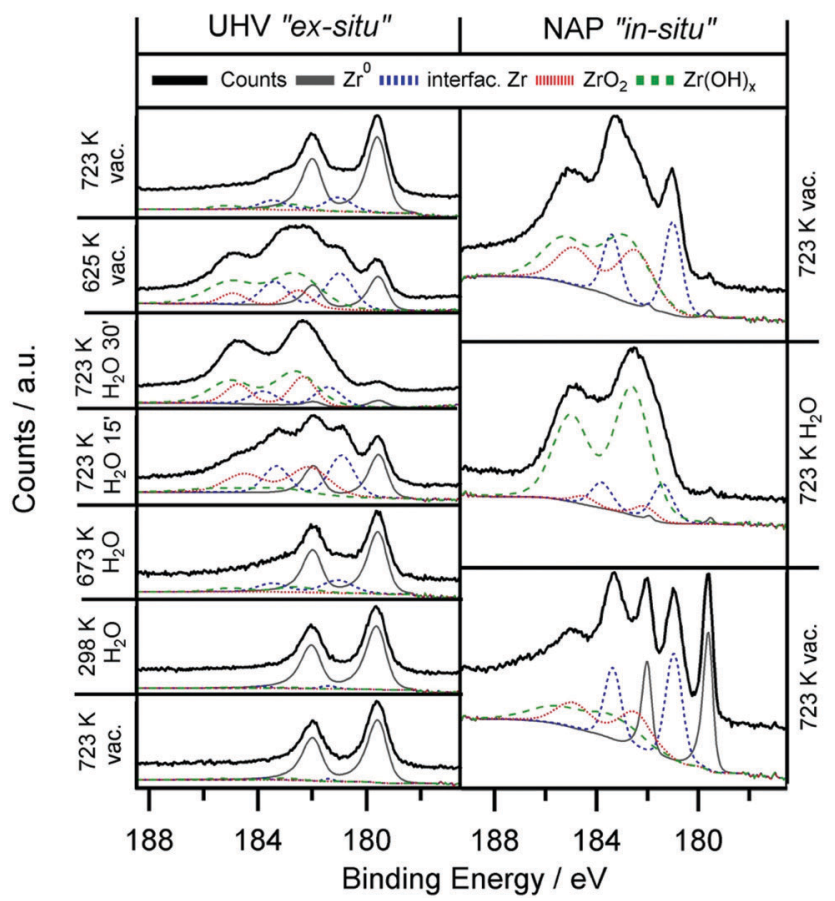

Fig. $6 \mathrm{Zr} 3 \mathrm{~d}$ spectra obtained ex situ and in situ during heating of $0.2 \mathrm{ML}$ $\mathrm{Zr} / \mathrm{ZrO}_{x} \mathrm{H}_{y}$ in water. $\mathrm{Zr}^{0} / \mathrm{ZrO}_{x} \mathrm{H}_{y}$ is prepared by annealing of CVD-grown $\mathrm{ZrO}_{x} \mathrm{H}_{y}$ (at $673 \mathrm{~K}, 2000 \mathrm{~L}$ ZTB) in $5 \times 10^{-11} / 5 \times 10^{-8}$ mbar for the ex situ and in situ experiment, respectively. Left panels: ex situ UHV XPS experiments on $\mathrm{Pd}(111)$, water pressure $5 \times 10^{-7}$ mbar. Right panels: in situ NAP-XPS experiments on a $\mathrm{Pd}$ foil, water pressure $0.3 \mathrm{mbar}$ for $20 \mathrm{~min}$. to the higher $\mathrm{H}_{2} \mathrm{O}$ pressure. The $\mathrm{Zr} 3 \mathrm{~d}_{5 / 2}$ peak of hydroxylated $\mathrm{Zr}^{4+}$ differs from the fully oxidized state and is found at around $183.0 \mathrm{eV}$, which complies well with literature values. ${ }^{51}$

Only in the UHV ex situ experiment the hydroxylation process is fully reversible: annealing at $723 \mathrm{~K}$ fully re-establishes the metallic state of Zr. Most likely, the degree of reversibility of the reduction process is highly dependent on the background pressure of oxygen containing molecules such as $\mathrm{H}_{2} \mathrm{O}$ and $\mathrm{O}_{2}$ in the residual gas.

Even though a catalytic reforming cycle should rather involve reversibly formed hydroxyl groups at $\mathrm{Zr}$ sites, an analogous experiment can also be performed with $\mathrm{O}_{2}$ instead of $\mathrm{H}_{2} \mathrm{O}$. Oxidative treatments in $\mathrm{O}_{2}$ (ex situ) and $0.3 \mathrm{mbar}_{2}$ (in situ) leads in both cases to fully oxidized $\mathrm{ZrO}_{2}$. Oxidation in $5 \times 10^{-7}$ mbar $_{2}$ for the ex situ experiments is fast, after 10 min no more metallic $\mathrm{Zr}$ is found. Again, full reversibility to the Zr metal state is only achieved in the UHV chamber. Wateranalogous results are also obtained for the in situ experiments with $0.3 \mathrm{mbar}_{2}$ pressure. Here, again only partially reversible reduction is possible, highlighting the aforementioned limitations by the poorer background pressure.

3.1.4. DFT calculations of the initial stages of $\mathrm{ZrO}_{2}$ reduction. To better understand the energetic pre-conditions leading to the pronounced reducibility of ultrathin $\mathrm{ZrO}_{2}$ films on Pd surfaces, DFT calculations with variable $\mathrm{ZrO}_{2}$ film thickness were performed. The reaction energy for deposition of a $\mathrm{ZrO}_{2}$ film on the $\mathrm{Pd}(111)$ surface, as cut from the $\mathrm{ZrO}_{2}$ bulk structure, is calculated by eqn (7) (see Section 2, "Computational methods"). The corresponding reaction energies $\Delta E$ for $1 \mathrm{ML}, 2 \mathrm{ML}$, and $3 \mathrm{ML}$ thick $\mathrm{ZrO}_{2}$ are $1.20,1.14$ and $1.20 \mathrm{~J} \mathrm{~m}^{-2}$, indicating that the $2 \mathrm{ML} \mathrm{ZrO}_{2}$ film is more stable than its $1 \mathrm{ML}$ and $3 \mathrm{ML}$ counterparts. The positive value of the reaction energy indicates that the process of cutting layers from the cubic $\mathrm{ZrO}_{2}$ bulk structure and depositing them as an ultrathin $\mathrm{ZrO}_{2}$ film on the Pd substrate is endothermic. To better understand the deposition of the $\mathrm{ZrO}_{2}$ films, the reaction energy $\Delta E$ is separated into two parts, the formation energy $\Delta E_{\text {film }}$ of the respective $\mathrm{ZrO}_{2}$ film from the bulk $\mathrm{ZrO}_{2}$ structure, and the adsorption energy $\Delta E_{\text {ads }}$ of this film on the Pd substrate. Our calculations show that the formation of a freestanding $\mathrm{ZrO}_{2}$ monolayer from the bulk structure would require an energy of $3.59 \mathrm{eV}$ and an equilibrium lattice compressed by $\sim 9 \%$. The corresponding adsorption energy $\Delta E_{\text {ads }}$ for the $1 \mathrm{ML} \mathrm{ZrO}_{2}$ film on the Pd substrate is $-0.11 \mathrm{eV}$. Formation of a freestanding $2 \mathrm{ML} \mathrm{ZrO}_{2}$ film from the bulk structure would require an energy of $5.09 \mathrm{eV}$ and an equilibrium lattice compression of $\sim 4 \%$. The corresponding adsorption energy $\Delta E_{\text {ads }}$ for the $2 \mathrm{ML} \mathrm{ZrO}_{2}$ film at the $\mathrm{Pd}(111)$ surface is $-1.81 \mathrm{eV}$. To form a freestanding $3 \mathrm{ML}$ $\mathrm{ZrO}_{2}$ film from the bulk structure would require an energy of $5.66 \mathrm{eV}$ and an equilibrium lattice compression of $\sim 3 \%$. The corresponding adsorption energy $\Delta E_{\text {ads }}$ for the $3 \mathrm{ML} \mathrm{ZrO}_{2}$ film and Pd substrate is $-2.18 \mathrm{eV}$. The lattice compression of $\mathrm{ZrO}_{2}$ film with respect to the ideal bulk structure was observed in previous theoretical calculations. ${ }^{52}$ With increasing thickness, the film lattice slowly approached the bulk lattice dimensions. It is noted that the $1 \mathrm{ML} \mathrm{ZrO}_{2}$ film exhibits the smallest 
adsorption energy, which is partially due to the strongest film reconstruction among the discussed 1-3 ML scenarios. In summary, the $3 \mathrm{ML} \mathrm{ZrO}_{2}$ film is less stable than the $2 \mathrm{ML}$ one due to the required larger film formation energy from the $\mathrm{ZrO}_{2}$ bulk, and the $1 \mathrm{ML} \mathrm{ZrO}_{2}$ film is less stable than the $2 \mathrm{ML}$ one due to the smaller adsorption energy at the Pd substrate.

We then investigated three possible competing reactions for oxygen atom removal: to release $0.5 \mathrm{O}_{2}$ into the gas phase directly, to dissolve an $\mathrm{O}$ atom into the $\mathrm{Pd}$ sub-layer and to diffuse the $\mathrm{O}$ atom to the available neighboring bare $\operatorname{Pd}(111)$ surface. The free reaction energy at $725 \mathrm{~K}$, calculated for an equilibrium pressure above the surface of $P_{\mathrm{O}_{2}}=10^{-12} \mathrm{mbar}$, is summarized in Table 1. Among the three possible competing reactions the interface oxygen diffusion to the neighboring bare $\operatorname{Pd}(111)$ surface is in any case the most favorable, followed by direct desorption into the gas phase as $0.5 \mathrm{O}_{2}$ and dissolution into the Pd sub-layer, which is the least favorable. The corresponding reaction energies for the interface-to-Pd oxygen diffusion are $0.74,1.43$, and $0.94 \mathrm{eV}$ for the $1 \mathrm{ML}, 2 \mathrm{ML}$ and $3 \mathrm{ML}$ thick $\mathrm{ZrO}_{2}$ films, respectively, while the direct desorption of $0.5 \mathrm{O}_{2}$ into the gas phase is $\sim 0.20 \mathrm{eV}$ higher than the diffusion. The corresponding reaction energies for oxygen dissolution in the Pd sub-layer amount to 2.00, 3.09 and $2.48 \mathrm{eV}$, which is in all cases much higher than the diffusion to the neighboring $\operatorname{Pd}(111)$ surface. We also found that the surface oxygen of the topmost layer and the interface oxygen of the lowest layer show the same reactivity for the direct $\mathrm{O}_{2}$ desorption for the $1 \mathrm{ML}$ and $2 \mathrm{ML} \mathrm{ZrO}_{2}$ films. However, for the $3 \mathrm{ML} \mathrm{ZrO}_{2}$ film, the interface oxygen is more active than the surface oxygen, indicating that the oxygen vacancy is more stable at the interface than at the outer surface. The corresponding structures for oxygen diffusion to the neighboring $\operatorname{Pd}(111)$ surface and dissolution into the sub-layer of the Pd substrate are shown in Fig. 7. As shown therein, the surface Pd atom moves up significantly by $\sim 0.40-0.50 \AA$ in order to adapt the dissolved oxygen atom. In Table 1, we also included the movement of an interface $\mathrm{Zr}$ atom. As expected, atomic $\mathrm{Zr}$ dissolution from the interface to the Pd sub-layer is less favorable than atomic oxygen dissolution due to the large size of atomic Zr. The corresponding reaction energies are 2.78, 3.45 and $3.29 \mathrm{eV}$ for the

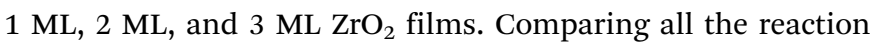
energies, it is noted that to move either $\mathrm{O}$ or $\mathrm{Zr}$ from the $2 \mathrm{ML}$ $\mathrm{ZrO}_{2}$ film is more difficult than that from the $1 \mathrm{ML}$ and $3 \mathrm{ML}$ films, suggesting that the $2 \mathrm{ML}$ arrangement is the most stable one.

Table 1 Calculated reaction energy $\Delta G_{\text {diss }}(\mathrm{eV})$ of $\mathrm{O} / \mathrm{Zr}$ dissolution into the $\mathrm{Pd}$ sub-layer, reaction Gibbs free energy $\Delta G_{\mathrm{O}_{2}}(\mathrm{eV})$ of $\mathrm{O}_{2}$ production in the gas phase, reaction energy $\Delta G_{\text {diff }}(\mathrm{eV})$ of $\mathrm{O}$ diffusion to the available neighboring bare $\mathrm{Pd}(111)$ surface at $725 \mathrm{~K}$ with $P_{\mathrm{O}_{2}}=10^{-12} \mathrm{mbar}$

\begin{tabular}{llll}
\hline $\mathrm{ZrO}_{2}$ & 1 layer & 2 layer & 3 layer \\
\hline$\Delta G_{\text {diss }}\left(\mathrm{O}_{\left.\text {interface } \rightarrow \mathrm{O}_{\text {sub-layer } / \mathrm{Pd}}\right)}\right.$ & 2.00 & 3.09 & 2.48 \\
$\Delta G_{\mathrm{O}_{2}}\left(\mathrm{O}_{\text {interface }} \rightarrow 0.5 \mathrm{O}_{2}\right)$ & 0.94 & 1.63 & 1.14 \\
$\Delta G_{\mathrm{O}_{2}}\left(\mathrm{O}_{\text {surface }} \rightarrow 0.5 \mathrm{O}_{2}\right)$ & 0.94 & 1.68 & 1.46 \\
$\Delta G_{\text {diff }}\left(\mathrm{O}_{\text {interface }} \rightarrow \mathrm{O}_{\mathrm{Pd}}\right)$ & 0.74 & 1.43 & 0.94 \\
$\Delta G_{\text {diss }}\left(\mathrm{Zr}_{\text {interface }} \rightarrow \mathrm{Zr}_{\text {sub-layer/Pd }}\right)$ & 2.78 & 3.45 & 3.29
\end{tabular}

As discussed above, among the three possible competing reactions the interface oxygen rather prefers to diffuse to the available neighboring bare $\operatorname{Pd}(111)$ surface. Following this process, atomic oxygen may recombine to desorb as $\mathrm{O}_{2}$ from the Pd surface. A number of previous experimental and theoretical studies have investigated $\mathrm{O}_{2}$ adsorption/desorption on the $\operatorname{Pd}(111)$ surface. ${ }^{53-57}$ Using thermal desorption spectrometry, one of our previous studies showed that the $\mathrm{O}_{2}$ desorption rate from a chemisorbed $\mathrm{O}(\mathrm{ads})$ layer on $\mathrm{Pd}(111)$ reached its maximum at $\sim 750 \mathrm{~K}$, which implies that associative $\mathrm{O}_{2}$ desorption from bare $\mathrm{Pd}$ is both possible and irreversible under the UHVreduction conditions chosen in the present study. ${ }^{58}$

The conclusions from this section regarding the optimum growth conditions for subsequent full reducibility are: (i) preferential single layer growth of $\mathrm{ZrO}_{2}$ and (ii) a large phase boundary of the sub-monolayer $\mathrm{ZrO}_{2}$ islands toward the surrounding bare Pd surface should be realized already during the deposition process.

\subsection{Catalytic results}

To correlate the redox chemistry of $\mathrm{Zr}$ on $\mathrm{Pd}$ with catalytic properties, the previously discussed Pd-Zr systems have been tested in two model reactions: methanol steam reforming and dry reforming of methane. While for the former no catalytically promoting role has been found (for an overview of the catalytic results, see ESI, $\uparrow$ Section F, Fig. S4-S6), the latter is clearly promoted by Zr doping of Pd. These experiments, which show the opening of new $\mathrm{CO}_{2}$ activation channels on $\mathrm{Pd}$, are now discussed in Section 3.2.1.

3.2.1. Dry reforming of methane (DRM). To account for the eventual promoting role of $\mathrm{Zr}$, the mixed valence $\mathrm{Pd} / \mathrm{Zr}^{0} / \mathrm{ZrO}_{x} \mathrm{H}_{y}$ model catalyst (again prepared by annealing of CVD grown $\mathrm{ZrO}_{x} \mathrm{H}_{y}$ in vacuum), as well as the $\mathrm{Pd}: \mathrm{Zr}=2: 1$ intermetallic "IM" reference catalyst described in the experimental section, are tested for methane dry reforming ( $\mathrm{DRM}, \mathrm{CH}_{4}+\mathrm{CO}_{2} \rightarrow 2 \mathrm{CO}+2 \mathrm{H}_{2}$ ). For this reaction, no initial water activation is required, but active sites both for $\mathrm{CO}_{2}$ and $\mathrm{CH}_{4}$ activation are mandatory. Water can in principle play a "co-catalytic" role as an intermediate or spoil the reaction as a side product, if $\mathrm{CH}_{4}$ is not stoichiometrically converted and the inverse WGS reaction is active:

$$
\begin{aligned}
& \text { Water-free } \\
& \mathrm{CH}_{4} \rightarrow \mathrm{C}+2 \mathrm{H}_{2} \\
& \mathrm{C}+\mathrm{CO}_{2} \rightarrow 2 \mathrm{CO}
\end{aligned}
$$

$$
\begin{aligned}
& \text { Water-involving } \\
& \mathrm{CH}_{4} \rightarrow \mathrm{C}+2 \mathrm{H}_{2} \\
& \mathrm{CO}_{2}+\mathrm{H}_{2} \rightarrow \mathrm{CO}+\mathrm{H}_{2} \mathrm{O} \\
& \mathrm{C}+\mathrm{H}_{2} \mathrm{O} \rightarrow \mathrm{CO}+\mathrm{H}_{2}
\end{aligned}
$$

The results of the DRM experiments are shown in Fig. 8. In none of the catalytic experiments shown therein, $\mathrm{H}_{2} \mathrm{O}$ was detected, thus, at least the side reaction to water associated with the inverse WGS reaction is of minor importance. Carbon was detected with XPS on the surface after the reaction, but in too low amounts (relative to the gaseous reactant/product amounts) to affect the overall stoichiometry. Fig. 8 displays the DRM selectivity/activity pattern for a choice of "monofunctional" 
(a)

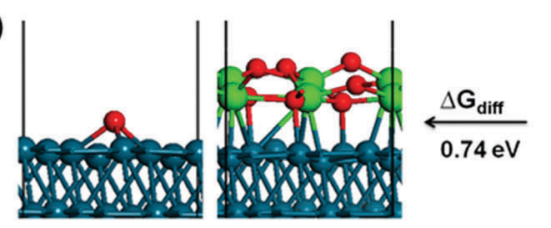

(b)

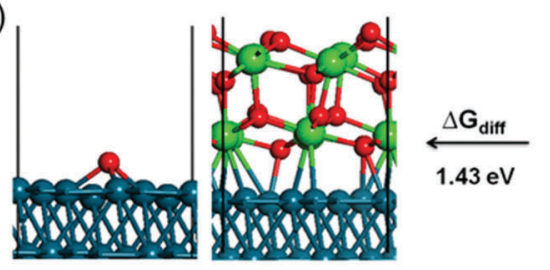

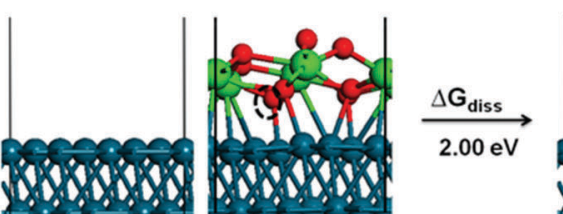
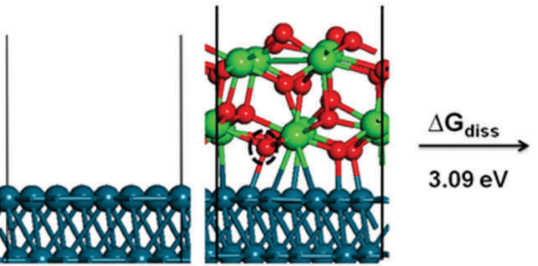
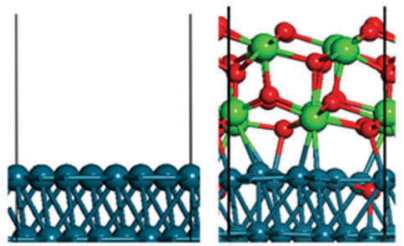

(c)
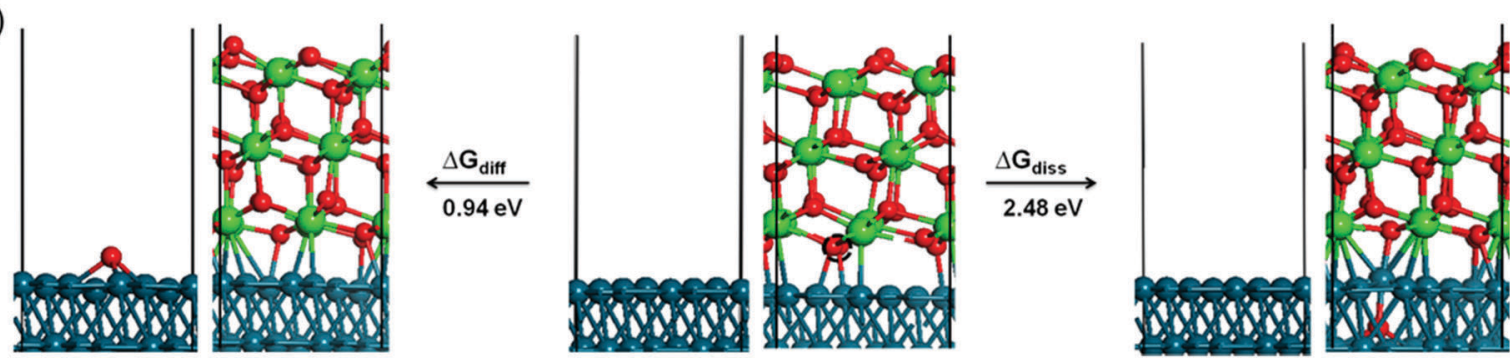

Fig. 7 Structural models of interface oxygen dissolution to the sub-layer of $\mathrm{Pd}(111)$ and diffusion to the available neighboring bare $\mathrm{Pd}(111)$ surface. The reaction energies are labeled. Left: the $\mathrm{Pd}-\mathrm{O}$ diffusion scenario; right: dissolution scenario; middle: 1 (a), 2 (b), and 3 (c) ML ZrO 2 on the $\mathrm{Pd}(111)$ substrate. The moving $\mathrm{O}$ atom is marked by a dashed black circle. Small red spheres: $\mathrm{O}$; large green spheres: $\mathrm{Zr}$; blue spheres: Pd. The boxes indicate the computational supercell.

(pure $\mathrm{Pd}$ or $\mathrm{Zr}$ ) and "bifunctional" ( $\mathrm{Pd}-\mathrm{Zr}$ ) model catalysts. Clean $\mathrm{Pd}$ is completely inactive, as well as clean $\mathrm{ZrO}_{2}$. Fig. 9 shows the corresponding XP spectra before and after selected DRM experiments of Fig. 8. A pure $\mathrm{Zr}$ metal foil was oxidized in $1 \mathrm{bar} \mathrm{O}_{2}$ at $673 \mathrm{~K}$ to form a $\mathrm{ZrO}_{2}$ layer that is thicker than the XPS analysis depth $\left(95 \%\right.$ of signal from topmost $5 \mathrm{~nm}$ for $\mathrm{ZrO}_{2}$ with $\mathrm{Mg} \mathrm{K} \alpha$ radiation). After the DRM reaction, the $\mathrm{ZrO}_{2}$ film is reduced within the accessible information depth and a single state of $\mathrm{Zr}$ is detected in the XPS $3 \mathrm{~d}$ region at a binding energy of $179.4 \mathrm{eV}$, which agrees well both with literature $\mathrm{BE}$ values of $\mathrm{Zr}^{050}$ and zirconium carbide ZrC. ${ }^{59}$ Destructive (sputter) depth profiling of this surface after catalysis is shown in the ESI $\dagger$ in Fig. S7, revealing a thickness of the carburized $\mathrm{ZrC}$ layer on top of $\mathrm{Zr}$ of at least $20 \mathrm{~nm}$.

For the CVD-prepared and then vacuum- or oxygen-annealed $\mathrm{Pd} / \mathrm{Zr}^{0} / \mathrm{ZrO}_{x} \mathrm{H}_{y}$ or $\mathrm{Pd} / \mathrm{ZrO}_{2}$ samples, the activity in DRM depends on the initial oxidation state of $\mathrm{Zr}$. As soon as there is a small fraction of $\mathrm{Zr}^{0}$ available in the pre-catalyst (see arrow in Fig. 9), a measurable $\mathrm{CO}$ formation rate could be detected. In Fig. 8, the reaction rate is multiplied by a factor of 30 to show that there is some $\mathrm{CO}_{2}$ consumed and $\mathrm{CO}$ formed at the stoichiometric ratio $1: 2$, but at a $30 \times$ lower rate as compared to the bulk-intermetallic "IM" catalyst described below. Again, no water side product formation could be detected. The temperatureprogrammed reaction profile for fully oxidized $\mathrm{ZrO}_{2}$ on $\mathrm{Pd}$ (generated by annealing of the "as-grown" CVD layer in $\mathrm{O}_{2}$ at $750 \mathrm{~K}$ ) is not shown since no reactivity at all was detected, but the XP spectra for both $\mathrm{ZrO}_{2}$ and $\mathrm{ZrO}_{x} \mathrm{H}_{y} / \mathrm{Zr}^{0}$ on $\mathrm{Pd}$ are shown in Fig. 9 before and after DRM. On this basis, the fundamental activating function of $\mathrm{Zr}^{0}$, which becomes in situ oxidized during DRM, could be shown qualitatively in spite of the very small initial $\mathrm{Zr}^{0}$ amount. In order to substantiate this result, we decided to test an all-intermetallic bulk phase of Pd and $\mathrm{Zr}$ in the stoichiometry of $2: 1$ under otherwise identical DRM conditions ("IM" sample prepared by strongly exothermic co-melting, see chapter 2). The sample gets (surface) oxidized at room temperature over time, leading to a loss of $\mathrm{Zr}^{0}$ in XPS (analysis depth $\sim 2-3 \mathrm{~nm}$ ). This oxidation was not found to be crucial for the catalyst performance. It does not matter whether $\mathrm{Pd}-\mathrm{Zr}$ intermetallic is surface pre-oxidized in air at room temperature almost within the XPS analysis depth (Fig. 9). The "before DRM" - IM spectra in Fig. 9 shows the most air-oxidized state right before the catalytic experiment. Nevertheless, it shows residual $\mathrm{Zr}^{0}$.

On this sample, the formation rate of $\mathrm{CO}$ is $\sim 30$ times higher than on the vacuum annealed CVD $\mathrm{Pd} / \mathrm{Zr}^{0} / \mathrm{ZrO}_{x} \mathrm{H}_{y}$ sample. This substantiates our interpretation that the (in situ) oxidative segregation from an initially intermetallic phase and/ or surface leads to an enhanced number of reforming-active interfacial $\mathrm{Pd} / \mathrm{ZrO}_{x} \mathrm{H}_{y}$ sites. Again, we suggest the idea that the (in situ) oxidation of an atomically homogeneous intermetallic phase leads to the most disperse $\mathrm{Zr}^{4+} \mathrm{O}_{x} \mathrm{H}_{y}$ surface-near distribution possible and therefore, to a maximum number of $\mathrm{Pd} / \mathrm{Zr}^{4+} \mathrm{O}_{x} \mathrm{H}_{y}$ interface sites, i.e. to a quasi "atomically dispersed" phase boundary. The validity of this concept has 


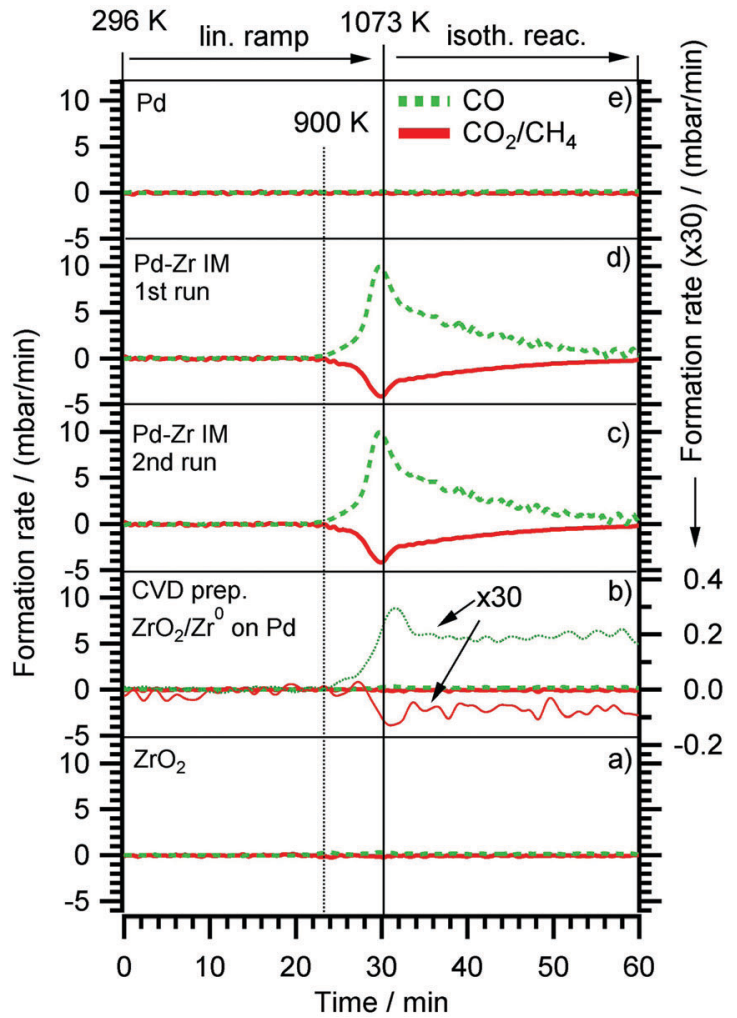

Fig. 8 Methane dry reforming (DRM) on (a) Clean oxidized Zr foil (identical with pattern for $0.3 \mathrm{ML} \mathrm{ZrO}$ on $\mathrm{Pd}$, prepared by post annealing of CVD grown $\mathrm{ZrO}_{x} \mathrm{H}_{y}$ in $5 \times 10^{-7} \mathrm{mbar}_{2}$ at $700 \mathrm{~K}$ ). (b) $0.3 \mathrm{ML} \mathrm{Zr} / \mathrm{ZrO}_{x} \mathrm{H}_{y}$, prepared by annealing of CVD grown $\mathrm{ZrO}_{x} \mathrm{H}_{y}$ in $5 \times 10^{-9}$ mbar vacuum (the reactant consumption- and $\mathrm{CO}$ product formation rates were multiplied by a factor of 30 and plotted in the Y-scale range of the "IM" experiments ( $c$ and $d$ ) two consequent DRM runs of an intermetallic $\mathrm{Pd}: \mathrm{Zr}=$ 2:1 "IM" bulk phase, (e) pure Pd. Initial DRM conditions: $\mathrm{CO}_{2}: \mathrm{CH}_{4}=1: 1$, total reactant pressure $100 \mathrm{mbar}$ ).

previously been proven for $\mathrm{Cu} / \mathrm{Zn}^{12}, \mathrm{Pd} / \mathrm{Zn}^{13}$ and $\mathrm{Cu} / \mathrm{Zr}^{11}$ and is now also confirmed for Pd/Zr. The enhanced DRM reactivity on the $\mathrm{Pd} / \mathrm{Zr}^{0} / \mathrm{ZrO}_{x} \mathrm{H}_{y}$ pre-catalyst is therefore mainly assigned to the synergistic action of very small $\mathrm{Zr}^{0}$ clusters, which become partially oxidized and/or hydroxylated under reaction conditions and exhibit a high number of direct Pd neighbours. Obviously, the number of these desirable interfacial sites is even higher on the in situ oxidized IM bulk phase pre-catalyst, eventually leading to a 30 times higher reaction rate.

Note that no deactivation of the IM catalyst was found on the time scale of our experiments $(2 \times 60 \mathrm{~min}$ each, 1 st and 2 nd run). In both cases, the decrease of the reaction rate in the isothermal reaction section is due to complete consumption of $\mathrm{CO}_{2}$ and $\mathrm{CH}_{4}$, as the reactor is operated in re-circulating batch mode. This reproducibility and stability with respect to catalytic performance holds despite a huge amount of carbon deposition (or, possibly, surface segregation) after cooling in the reaction mixture (see C 1s region of uppermost panel in Fig. 9). The binding energy of $\sim 284.5 \mathrm{eV}$ and the rather large peak width (as compared to pure graphite) suggest a mix of $\mathrm{sp}^{3}$ - or $\mathrm{sp}^{2}$-hybridized carbon species. The carbon layer is thick enough for complete shielding of both the Pd and $\mathrm{Zr}$ signals. This renders

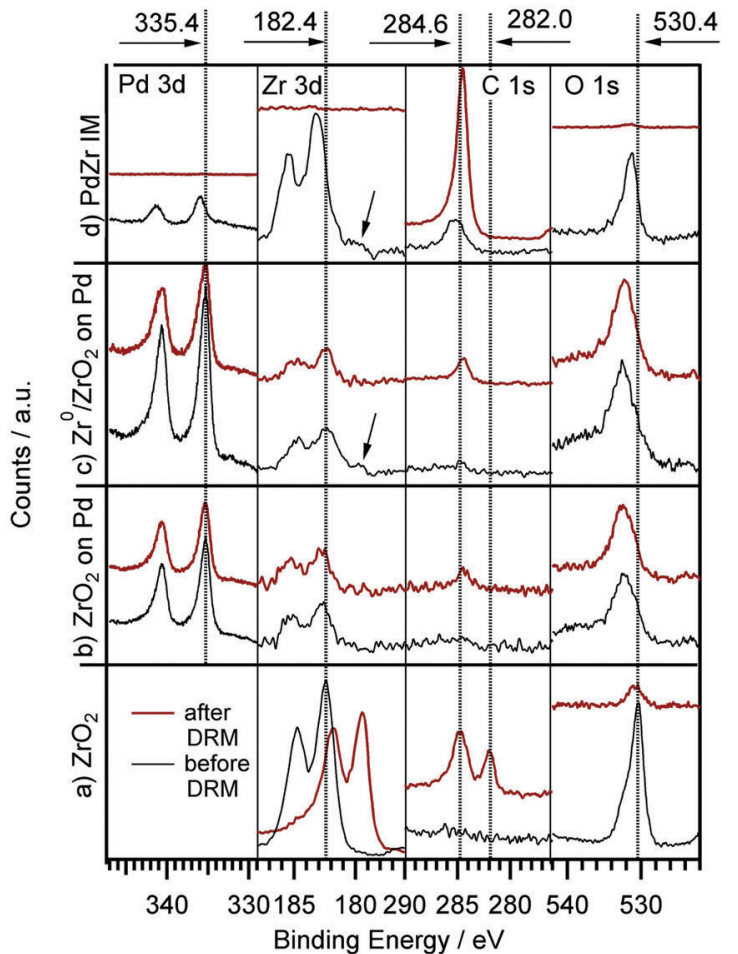

Fig. 9 XPS (Pd 3d, Zr 3d, C 1s and O 1s (overlapping with $P d 3 p$ ) region) before and after DRM experiments for: (a) clean $\mathrm{Zr}$ foil, pre-oxidized in $5 \times 10^{-7} \mathrm{mbar} \mathrm{O}_{2}$ at $750 \mathrm{~K}$ for $15 \mathrm{~min}$; (b) $0.3 \mathrm{ML} \mathrm{ZrO}_{2}$ on Pd, prepared by thermal annealing of CVD grown $\mathrm{ZrO}_{x} \mathrm{H}_{y}$ in $5 \times 10^{-7} \mathrm{mbar}_{2}$ at $700 \mathrm{~K}$; (c) $0.3 \mathrm{ML} \mathrm{Zr} / / \mathrm{ZrO}_{x} \mathrm{H}_{y}$, prepared by annealing of a CVD grown $\mathrm{ZrO}_{x} \mathrm{H}_{y}$ in $5 \times 10^{-9}$ mbar vacuum at $700 \mathrm{~K}$; (d) intermetallic $\mathrm{Pd} / \mathrm{Zr}$ (2:1) "IM" bulk phase before first and after second DRM run. The arrow indicates the $\mathrm{Zr}^{0}$ component.

the absent deactivation of the catalyst after the first run even more surprising. Apparently, the catalytically active sites become again accessible during heating, e.g. if the carbon layer is reacted off by $\mathrm{CO}_{2}$ and/or becomes re-dissolved in the bulk. Since the reaction sets in at $\sim 900 \mathrm{~K}$, the onset of the Boudouard reaction might explain this phenomenon. A final note on the bulk structure of the DRM-tested intermetallic Pd-Zr sample should be provided at this point. As already outlined in Section 2 and further elaborated upon in the discussion of Fig. S8 (ESI $\dagger$ ), highlighting the X-ray diffractograms before and after the DRM reaction, despite the nominal $2: 1$ composition, the initial patterns reveal the presence of at least two intermetallic compounds with Pd excess, namely $\mathrm{Pd}_{3} \mathrm{Zr}$ and $\mathrm{Pd}_{4} \mathrm{Zr}_{3}$. Upon performing the DRM reaction, the patterns get even more complex, including the complete removal of the $\mathrm{Pd}_{3} \mathrm{Zr}$ phase and the formation of a new $\mathrm{Pd}_{9} \mathrm{Zr}$ phase. Elementary, graphite-like carbon and partially oxidized $\mathrm{ZrO}_{2}$ in the monoclinic and tetragonal modifications, formed by partial (oxidative) decomposition of the $\mathrm{Pd}-\mathrm{Zr}$ intermetallic compounds, are equally observed. This is in striking contrast to $\mathrm{Cu}-\mathrm{Zr}$, where only one $\mathrm{Cu}_{51} \mathrm{Zr}_{14}$ compound was observed after preparation. ${ }^{24} \mathrm{~A}$ common behavior (despite the different reactions) are the massive operando observed bulk structural changes accompanying the surface chemical alterations. However, due to the initially less homogeneous melt in the Pd-Zr case, the structural complexity is significantly more pronounced. 


\section{Conclusions}

The CVD process of zirconium-t-butoxide ZTB was studied on $\operatorname{Pd}(111)$ single crystal and on polycrystalline Pd foil samples. A substrate temperature of $\sim 700 \mathrm{~K}$ was found to be ideal to create a partially hydroxylated, carbon-depleted and vacuumreducible $\mathrm{ZrO}_{x} \mathrm{H}_{y}$ overlayer. Depending on the quality of the vacuum conditions, reversible partial or full reduction of the $\mathrm{ZrO}_{x} \mathrm{H}_{y}$ overlayer (i.e. $\mathrm{Zr}^{4+}$ ) to surface $\mathrm{Zr}^{0}$ nanoclusters could then be accomplished. This very dynamic redox behaviour of $\mathrm{ZrO}_{x} \mathrm{H}_{y}$ overlayers on $\mathrm{Pd}$ manifests itself in repeated oxidation (in water or oxygen) and vacuum-reduction cycles to the adsorbed $\mathrm{Zr}^{0}$ metallic state without alloying up to $770 \mathrm{~K}$. Nanoclusters of 2-6 $\mathrm{Zr}^{0}$ atoms were found by STM if $\mathrm{Pd} / \mathrm{ZrO}_{x} \mathrm{H}_{y}$ was UHV-reduced at $723 \mathrm{~K}$. DFT calculations show that the interfacial oxygen, especially that of a single-layer cubic $\mathrm{ZrO}_{2}$ film, energetically prefers to diffuse to the available neighboring bare $\mathrm{Pd}(111)$ surface, rather than to desorb as $\mathrm{O}_{2}$ or to become dissolved in the Pd subsurface region.

CVD-prepared and vacuum-reduced $\mathrm{Pd} / \mathrm{Zr}^{0} / \mathrm{ZrO}_{x} \mathrm{H}_{y}$ model catalysts are not MSR active up to $623 \mathrm{~K}$, due to the formation of an interlayer of graphitic carbon between $\mathrm{Zr}$ and $\mathrm{Pd}$, resulting in the loss of active $\mathrm{Zr} / \mathrm{Pd}$ phase boundary sites. In contrast to the related $\mathrm{Cu} / \mathrm{ZrO}_{x} \mathrm{H}_{y}$ system, MSR on $\mathrm{Pd} / \mathrm{Zr}^{0} / \mathrm{ZrO}_{x} \mathrm{H}_{y}$ does, therefore, not proceed via the low $(<623 \mathrm{~K})$ temperature/partial dehydrogenation route with intermediate formaldehyde, which is thereafter totally oxidized by activated water to $\mathrm{CO}_{2}$. On $\mathrm{Zr}$-doped $\mathrm{Pd}$, rather, the expected full dehydrogenation of methanol toward CO takes place on the bare Pd surface patches, followed by the (also water-activation dependent) water gas shift route toward $\mathrm{CO}_{2}$ at higher temperatures above $\sim 650 \mathrm{~K}$. The latter process is only possible in the presence of an active $\mathrm{Pd} / \mathrm{ZrO}_{x} \mathrm{H}_{y}$ phase boundary, which is re-established above $\sim 650 \mathrm{~K}$ by reactive removal of carbon deposits.

Dry reforming activity with almost $100 \%$ CO-selectivity is only observed if $\mathrm{Zr}^{0}$ species either in a CVD-prepared/vacuumreduced or melt-prepared intermetallic $\mathrm{Pd}-\mathrm{Zr}$ "pre-catalyst" are initially present. With an intermetallic pre-catalyst bulk phase with a nominal 2:1 composition consisting of $\mathrm{Pd}^{0}$ and $\mathrm{Zr}^{0}$, the highest $\mathrm{CO}$ formation rates were obtained. At the surface of both systems, $\mathrm{Zr}^{0}$ is not stable under DRM conditions, and $\mathrm{Zr}^{4+} \mathrm{O}_{x} \mathrm{H}_{y}$ species are formed by in situ reactive oxidation/ hydroxylation. This process is likely to lead to a particularly high number of active phase boundary sites. As discussed above, further studies will most likely be focused on identifying sophisticated synthesis routines, allowing to prepare single-phase $\mathrm{Pd}-\mathrm{Zr}$ intermetallic compounds, whose intrinsic (catalytic) properties can, thus, be studied.

DFT calculations to describe the $\mathrm{Pd} / \mathrm{ZrO}_{x} \mathrm{H}_{y}$ induced $\mathrm{CO}_{2}$ activation and the reaction mechanism to $\mathrm{CO}$ and $\mathrm{H}_{2}$ are planned. Besides enhanced $\mathrm{CO}_{2}$ activation, also formation of surface adsorbed carbon from $\mathrm{CH}_{4}$ may be positively influenced by $\mathrm{Pd} / \mathrm{ZrO}_{x} \mathrm{H}_{y}$. The present study provides phenomenological evidence for an enhanced phase boundary synergism, including a beneficial carbon chemistry. Thus, theoretical studies of the microscopic reaction mechanism at the active sites are imperative, since $\mathrm{Zr}$ doping of Pd obviously opens up special $\mathrm{CO}_{2}$ activation pathways on chemically and electronically $\mathrm{Pd}$, which are not available on clean undoped metallic Pd.

\section{Acknowledgements}

L. Mayr and Z. Shi acknowledge financial support via FWF SFB "FOXSI" project part F4503-N16, L. Mayr via a scholarship of the Carinthian Confederation of Industry (Industriellenvereinigung Kärnten). The computational results presented have been achieved (in part) using the Vienna Scientific Cluster (VSC). Support from the Department of Energy, Office of Basic Energy Sciences, Chemical Sciences, under Grant DE-FG02-03ER15408 is gratefully acknowledged. The authors acknowledge the Purdue Catalysis Center, We are grateful to Michael Detwiler, Amir Gharachorlou, Ronald G. Reifenberger and Fabio H. Ribeiro for many helpful suggestions and motivating discussions. We also thank the Birck Nanotechnology Center staff for their assistance and cooperation throughout. We gratefully acknowledge the Helmholtz-ZentrumBerlin (HZB) for providing beamtime at the ISISS beamline.

\section{References}

1 K.-I. Fujimoto, F. H. Ribeiro, M. Avalos-Borja and E. Iglesia, J. Catal., 1998, 179, 431-442.

2 S. H. Liu, G. K. Chuah and S. Jaenicke, J. Mol. Catal. A: Chem., 2004, 220, 267-274.

3 D. He, Y. Ding, H. Luo and C. Li, J. Mol. Catal. A: Chem., 2004, 208, 267-271.

4 M. Behrens and M. Arnbrüster, Methanol Steam Reforming, in Catalysis for Alternative Energy Generation, ed. L. Guczi and A. Erdohelyi, Springer, New York, 2012, pp. 175-235.

5 P. Sudarsanam, B. Mallesham, P. S. Reddy, D. Großmann, W. Grünert and B. M. Reddy, Appl. Catal., B, 2014, 144, 900-908.

6 W. Du, G. Zhao, H. Chang, F. Shi, Z. Zhu and X. Qian, Mater. Charact., 2013, 83, 178-186.

7 A. Atkinson, S. Barnett, R. J. Gorte, J. T. S. Irvine, A. J. McEvoy, M. Mogensen, S. C. Singhal and J. Vohs, Nat. Mater., 2004, 3, 17-27.

8 R. L. Puurunen, J. Appl. Phys., 2005, 97, 121301.

9 J. P. Chang, Y.-S. Lin, S. Berger, A. Kepten, R. Bloom and S. Levy, J. Vac. Sci. Technol., B, 2001, 19, 2137-2143.

10 L. Mayr, N. Köpfle, A. Auer, B. Klötzer and S. Penner, Rev. Sci. Instrum., 2013, 84, 094103.

11 L. Mayr, B. Klötzer, D. Zemlyanov and S. Penner, J. Catal., 2015, 321, 123-132.

12 C. Rameshan, W. Stadlmayr, S. Penner, H. Lorenz, N. Memmel, M. Hävecker, R. Blume, D. Teschner, T. Rocha, D. Zemlyanov, A. Knop-Gericke, R. Schlögl and B. Klötzer, Angew. Chem., 2012, 124, 3057-3061.

13 C. Rameshan, W. Stadlmayr, C. Weilach, S. Penner, H. Lorenz, M. Hävecker, R. Blume, T. Rocha, D. Teschner, A. Knop-Gericke, R. Schlögl, N. Memmel, D. Zemlyanov, 
G. Rupprechter and B. Klötzer, Angew. Chem., Int. Ed., 2010, 49, 3224-3227.

14 S. Wang, G. Q. Lu and G. J. Millar, Energy Fuels, 1996, 10, 896-904.

15 P. Ferreira-Aparicio, A. Guerrero-Ruiz and I. Rodríguez-Ramos, Appl. Catal., A, 1998, 170, 177-187.

16 H. Ay and D. Üner, Appl. Catal., B, 2015, 179, 128-138.

17 N. H. Elsayed, N. R. M. Roberts, B. Joseph and J. N. Kuhn, Appl. Catal., B, 2015, 179, 213-219.

18 F. Kertis, J. Snyder, L. Govada, S. Khurshid, N. Chayen and J. Erlebacher, JOM, 2010, 62, 50-56.

19 M. Valden, X. Lai and D. W. Goodman, Science, 1998, 281, 1647-1650.

20 A. Gharachorlou, M. D. Detwiler, X. K. Gu, L. Mayr, B. Klötzer, J. Greeley, R. G. Reifenberger, W. N. Delgass, F. H. Ribeiro and D. Y. Zemlyanov, ACS Appl. Mater. Interfaces, 2015, 7, 16428-16439.

21 A. Gharachorlou, M. D. Detwiler, L. Mayr, X. K. Gu, J. Greeley, R. G. Reifenberger, W. N. Delgass, F. H. Ribeiro and D. Y. Zemlyanov, J. Phys. Chem. C, 2015, 119, 19059-19072.

22 A. Gharachorlou, M. D. Detwiler, A. V. Nartova, Y. Lei, J. Lu, J. W. Elam, W. N. Delgass, F. H. Ribeiro and D. Y. Zemlyanov, ACS Appl. Mater. Interfaces, 2014, 6, 14702-14711.

23 R. Paul, R. G. Reifenberger, T. S. Fisher and D. Y. Zemlyanov, Chem. Mater., 2015, 27, 5915-5924.

24 L. Mayr, D. Schmidmair, M. Armbrüster, N. Köpfle, J. Bernardi, S. Schwarz, B. Klötzer and S. Penner, ChemCatChem, 2016, 8, 1778-1781.

25 L. Mayr, R. Rameshan, B. Klötzer, S. Penner and C. Rameshan, Rev. Sci. Instrum., 2014, 85, 055104.

26 A. Knop-Gericke, E. V. Kleimenov, M. Hävecker, R. Blume, D. Teschner, S. Zafeiratos and R. Schlögl, Adv. Catal., 2009, 52, 213-272.

27 CasaXPS Version 2.3.16 Pre-rel 1.4, Casa Software Ltd, 2011.

28 C. D. Wagner, W. M. Riggs, L. E. Davis, J. F. Moulder and G. E. Muilenberg, Handbook of X-Ray Photoelectron Spectroscopy, Perkin-Elmer Corporation, Physical Electronics Division, Eden Prairie, Minnesota, 1979, vol. 55344.

29 D. Majumdar and D. Chatterjee, J. Appl. Phys., 1991, 70, 988-992.

30 C. J. Powell and A. Jablonski, NIST Electron EffectiveAttenuation-Length Database SRD 82, Version 1.3, Instititue of Standards and Technology, Gaithersburg, 2011.

31 J. J. Yeh, Atomic Calculation of Photoionization Cross-Sections and Asymmetry Parameters, Gordon and Breach Science Publishers, Langhorne, PE, USA, 1993.

32 G. Kresse and J. Furthmüller, Phys. Rev. B: Condens. Matter Mater. Phys., 1996, 54, 11169-11186.

33 G. Kresse and D. Joubert, Phys. Rev. B: Condens. Matter Mater. Phys., 1999, 59, 1758-1775.

34 J. Klimes, D. R. Bowler and A. Michaelides, J. Phys.: Condens. Matter, 2010, 22, 022201.

35 J. Klimeš, D. R. Bowler and A. Michaelides, Phys. Rev. B: Condens. Matter Mater. Phys., 2011, 83, 195131.

36 X.-R. Shi, S.-G. Wang, J. Hu, Z. Qin and J. Wang, Surf. Sci., 2012, 606, 1187-1194.
37 J. P. Chang, Y.-S. Lin and K. Chu, J. Vac. Sci. Technol., B, 2001, 19, 1782-1787.

38 M. A. Cameron and S. M. George, Thin Solid Films, 1999, 348, 90-98.

39 H. Gabasch, E. Kleimenov, D. Teschner, S. Zafeiratos, M. Hävecker, A. Knop-Gericke, R. Schlögl, D. Zemlyanov, B. Aszalos-Kiss, K. Hayek and B. Klötzer, J. Catal., 2006, 242, 340-348.

40 C. T. Lynch, K. S. Mazdiyasni, W. J. Crawford and J. S. Smith, Anal. Chem., 1964, 36, 2332-2336.

41 I. Martinko, R. Verhoef, Y. Engelmann, J. Cornil, S. Salah, R. Snyders, O. Antonin and P. Raynaud, 22nd International Symposium on Plasma Chemistry, 2015, vol. III, pp. 6-35.

42 R. Verhoef, P. Raynaud, S. Ligot, R. Snyders, T. Nelis, R. V. Gonzalez and S. Vitale, 21nd International Symposium on Plasma Chemistry, 2013, p. OR 214.

43 Y. Sert, L. M. Singer, M. Findlater, H. Dogan and G. Cirak, Spectrochim. Acta, Part A, 2014, 128, 46-53.

44 H. J. Oelichmann, D. Bougeard and B. Schrader, J. Mol. Struct., 1981, 77, 179-194.

45 H. J. Oelichmann, D. Bougeard and B. Schrader, J. Mol. Struct., 1981, 77, 149-163.

46 N. F. Brown and M. A. Barteau, J. Am. Chem. Soc., 1992, 114, 4258-4265.

47 M. W. Chase, J. Phys. Chem. Ref. Data, Monogr., 1998, 9, 1-1951.

48 J.-Q. Hu, M. Xie, Y. Pan, Y.-C. Yang, M.-M. Liu and J.-M. Zhang, Comput. Mater. Sci., 2012, 51, 1-6.

49 H. Li, J.-I. J. Choi, W. Mayr-Schmölzer, C. Weilach, C. Rameshan, F. Mittendorfer, J. Redinger, M. Schmid and G. Rupprechter, J. Phys. Chem. C, 2015, 119, 2462-2470.

50 S. Sinha, S. Badrinarayanan and A. P. B. Sinha, J. LessCommon Met., 1987, 134, 229-236.

51 C. Huang, Z. Tang and Z. Zhang, J. Am. Chem. Soc., 2001, 84, 1637-1638.

52 K. Meinel, A. Eichler, S. Förster, K. M. Schindler, H. Neddermeyer and W. Widdra, Phys. Rev. B: Condens. Matter Mater. Phys., 2006, 74, 235444.

53 F. P. Leisenberger, G. Koller, M. Sock, S. Surnev, M. G. Ramsey, F. P. Netzer, B. Klötzer and K. Hayek, Surf. Sci., 2000, 445, 380-393.

54 Y. Cao and Z.-X. Chen, Phys. Chem. Chem. Phys., 2007, 9, 739-746.

55 M. Ji, C. Hao, Z. Xie, S. Liu and J. Qiu, J. Comput. Theor. Nanosci., 2012, 9, 394-400.

56 J. Klikovits, E. Napetschnig, M. Schmid, N. Seriani, O. Dubay, G. Kresse and P. Varga, Phys. Rev. B: Condens. Matter Mater. Phys., 2007, 76, 045405.

57 H. Gabasch, W. Unterberger, K. Hayek, B. Klötzer, G. Kresse, C. Klein, M. Schmid and P. Varga, Surf. Sci., 2006, 600, 205-218.

58 B. Klötzer, K. Hayek, C. Konvicka, E. Lundgren and P. Varga, Surf. Sci., 2001, 482-485, 237-242.

59 R. Kaufmann, H. Klewe-Nebenius, H. Moers, G. Pfennig, H. Jenett and H. J. Ache, Surf. Interface Anal., 1988, 11, 502-509. 